\title{
CFHR5 Genetic Variations and Serum Levels in Patients with Immune- Complex-Mediated Membranoproliferative Glomerulonephritis and C3- Glomerulopathy
}

Nóra Garam ( $\nabla$ norigaram@gmail.com )

Semmelweis University https://orcid.org/0000-0002-1959-4473

Marcell Cserhalmi

Eotvos Lorand Tudomanyegyetem

Zoltán Prohászka

Semmelweis Egyetem

Ágnes Szilágyi

Semmelweis Egyetem

Nóra Veszeli

Semmelweis Egyetem

Edina Szabó

Semmelweis Egyetem

Barbara Uzonyi

Eotvos Lorand Tudomanyegyetem

Attila lliás

Eotvos Lorand Tudomanyegyetem

Christof Aigner

Medizinische Universitat Wien

Alice Schmidt

Medizinische Universitat Wien

Martina Gaggl

Medizinische Universitat Wien

Gere Sunder-Plassmann

Medizinische Universitat Wien

Dóra Bajcsi

Szegedi Tudomanyegyetem

Jürgen Brunner

Medizinische Universitat Innsbruck

Alexandra Dumfarth

Krankenhaus der Elisabethinen Linz

Daniel Cejka

krakenhaus der elisabethinen linz

Stefan Flaschberger

Hospital of Klagenfurt

Hana Flögelova

Univerzita Palackeho v Olomouci Fakulta Zdravotnickych ved

Agnes Haris

Szent Margit Korhaz

Ágnes Hartmann

Pecsi Tudomanyegyetem

Andreas Heilos

Medizinische Universitat Wien

Thomas Mueller

Medizinische Universitat Wien

Krisztina Rusai

Medizinische Universitat Wien

Klaus Arbeiter

Medizinische Universitat Wien

Johannes Hofer

Medizinische Universitat Innsbruck 
Dániel Jakab

Szegedi Tudomanyegyetem

Mária Sinkó

Szegedi Tudomanyegyetem

Erika Szigeti

Szegedi Tudomanyegyetem

Csaba Bereczki

Szegedi Tudomanyegyetem

Viktor Janko

Medimpax Sro

Kata Kelen

Semmelweis Egyetem

György S. Reusz

Semmelweis Egyetem

Attila J. Szabó

Semmelweis Egyetem

Nóra Klenk

FMC Center of Dialysis Miskolc

Krisztina Kóbor

FMC Center of Dialysis Miskolc

Nika Kojc

Univerza v Ljubljani

Maarten Knechtelsdorfer

wilhelminenspital vienna

Mario Laganovic

University Hospital Zagreb

Adrian Catalin Lungu

Institutul Clinic Fundeni

Anamarija Meglic

University medical center ljubljana

Rina Rus

university medical center ljubljana

Tanja Kersnik-Levart

University medical center Ljubljana

Emesta Macioniene

Vilniaus Universitetas

Marius Miglinas

Vilniaus Universitetas

Anna Pawłowska

Uniwersytet Warminsko-Mazurski

Tomasz Stompór

Uniwersytet Warminsko-Mazurski

Ludmila Podracka

comenius university

Michael Rudnicki

Medizinische Universitat Innsbruck

Gert Mayer

Medizinische Universitat Innsbruck

Romana Rysava

Charles university prague

Jana Reiterova

charles university prague

Marijan Saraga

University hospital Split

Tomáš Seeman

University hospital Motol

Jakub Zieg

Charles university prague

Eva Sládková 
University hospital of Plzen

Natasa Stajic

institute of mother and child healt care of serbia

Tamás Szabó

Debreceni Egyetem

Andrei Capitanescu

Carole Davila Nephrology hospital Bucharest

\section{Simona Stancu}

Carol Davila Nephrology Hospital Bucharest

\section{Miroslav Tisljar}

Zagreb medical university

\section{Kresimir Galesic}

zagreb medical university

András Tislér

Semmelweis Egyetem

Inga Vainumäe

Tartu University Hospital

Martin Windpessl

Klinikum Wels - Grieskirchen $\mathrm{GmbH}$

Tomas Zaoral

university hospital ostrava

Galia Zlatanova

University Children's Hospital Sofia

Mihály Józsi

Eotvos Lorand Tudomanyegyetem

Dorottya Csuka

Semmelweis Egyetem

\section{Research}

Keywords: membanoproliferative glomerulonephritis, immuncomplex-mediated glomeruloneohritis, C3 glomerulopathy, dense deposit disease, C3 glomerulonephritis

Posted Date: June 4th, 2020

DOI: https://doi.org/10.21203/rs.3.rs-32618/v1

License: (1) This work is licensed under a Creative Commons Attribution 4.0 International License. Read Full License 


\section{Abstract}

Background: Factor H-related-5 (FHR-5) is a member of the complement Factor $\mathrm{H}$ protein family. Due to the homology to Factor $\mathrm{H}$, the main complement regulator of the alternative pathway, it may also be implicated in pathomechanism of kidney diseases where Factor $\mathrm{H}$ and alternative pathway dysregulation play a role. Here, we report the first observational study on CFHR5 variations along with serum FHR-5 levels in immune-complex-mediated membranoproliferative glomerulonephritis (IC-MPGN) and C3 glomerulopathy (C3G) patients together with the clinical, genetic, complement and follow-up data.

Results: 120 patients with a histologically-proven diagnosis of IC-MPGN/C3G were enrolled in the study. FHR- 5 serum levels were measured in ELISA, the CFHR5 gene was analyzed by Sanger-sequencing, and selected mutants were studied as recombinant proteins in ELISA and SPR.

Eight relevant CFHR5 variations in 14 patients (11.7\%) were observed, 5 of them identified as pathogenic for C3G. The FHR-5 $278 \mathrm{~S}$ and FHR- $5_{\mathrm{R} 356 \mathrm{H}}$ mutations altered the interaction of FHR- 5 with C3b, when compared to the FHR- $5_{W T}$. Serum FHR- 5 levels were lower in patients compared to controls. Low serum FHR- 5 concentration at presentation associated with better renal survival during the follow-up period, furthermore, it showed clear association with signs of hypocomplementemia and clinically meaningful clusters.

Conclusions: Our observations support the hypothesis that FHR-5 protein and its genetic alterations play a role in the pathogenesis of IC-MPGN/C3G.

\section{Background}

Membranoproliferative glomerulonephritis (MPGN) is a well-characterized histological pattern on light microscopy (1). Current classification divides MPGN into complement-mediated C3 glomerulopathy (C3G) and immune-complex-mediated MPGN (IC-MPGN) based on the immunofluorescence microscopy findings where $\mathrm{C} 3$ staining is minimum two-order magnitude stronger than any other immunoreactant in case of C3G(2). C3G is further divided into C3 glomerulonephritis (C3GN) and dense deposit disease (DDD), where highly electrondense intramembranous deposits are localized in the glomerular basement membrane on electronmicroscopy (2). According to current classification, the dysregulation of the complement alternative pathway (AP) is responsible for C3G, which may be caused by autoantibodies against different complement components (e.g. C3 nephritic factor (C3NeF), C4 nephritic factor (C4NeF), C5 nephritic factor (C5NeF) (3), anti-Factor $\mathrm{H}$, anti-C3 (4) (5-8)) and/or (rare) variations in complement-associated genes (C3, CFH, CFI, CFB, THBD, CD46)(9-11). Interestingly, the above mentioned pathologic factors can be detected in only $30-80 \%$ of the patients $(1,5,9-14)$. However, in many cases there is no strict boundary between IC-MPGN and C3G or C3GN and DDD. Signs of AP dysregulation, such as decreased C3 or the presence of C3NeF, can be detected in ICMPGN as well and repeated biopsies may show changes in histology patterns $(2,15-17)$. For these reasons, we included both entities in our study. A novel, hypothesis-free, data-driven analysis of MPGN patients raised the possibility that clinically meaningful clusters may replace the histology-based classification (18). Furthermore, there are many cases with signs of AP dysregulation without any well-known pathogenic factor (13), but there are new candidates which may broaden the group of pathogenic factors. One potential candidate is complement Factor $\mathrm{H}(\mathrm{FH})$-related protein 5 (FHR-5), which was first described in 2001 (19). FHR-5 is a member of the complement FH protein family (FHR), which consist of the AP complement inhibitors FH and FH-like 1, which are derived by alternative splicing from $\mathrm{CFH}$, and $5 \mathrm{FH}$-related (FHR) proteins that are highly homologous to $\mathrm{FH}$, but their functions are not fully understood (20). This homology raises the possibility that FHRs can compete with FH for the binding of C3b $(21,22)$. Moreover, FHR-5 can bind to heparin, C-reactive protein, pentraxin-3 and the extracellular matrix $(21,23)$ and it can also inhibit the C3- and C5-convertases based on previous studies $(21,24,25))$. FHR-5 was described as a pathogenic factor in a subtype of C3G $(26,27)$. This hereditary, endemic form in Cyprus was named CFHR5-nephropathy, which is caused by an internal duplication of exons 2 and 3 of the CFHR5 gene (27). This entity presents with synpharingitic macroscopic hematuria with renal failure (28). In recent years, genetic analysis of CFHR5 in several conditions such as atypical hemolytic uremic syndrome (aHUS), IgA-nephropathy (IgAN) or MPGN explored a potential connection with these pathological states $(26,29-31)$ but the exact pathophysiological role of FHR-5 is still unknown. Large case series studies which examined the patients' FHR-5 levels have been performed only in patients with IgAN $(32,33)$. Interestingly, FHR-5 serum levels were elevated in patients with IgAN and showed an association with disease progression $(32,33)$. In a small cohort of 23 C3GN patients lower FHR-5 levels were detected compared to healthy controls (34). Moreover, genetic variations of CFHR5 were described in a C3G cohort of 104 patients. (35) Probably not only the FHR proteins's plasma levels, but modified FHR and FH plasma repertoire may also affect the complement regulation on the endothelial surface or in the fluid-phase resulting in cell injury. Interactions with glycosaminoglycans can also affect the functions of the above mentioned proteins (25). However, detailed genetic and functional analysis of CFHR5 along with the parallel measurement of serum levels of the protein have not been performed in a large number of IC-MPGN and C3G patients.

Our aim was to screen the sequence of CFHR5 in a large group of patients with IC-MPGN/C3G, and to functionally characterize CFHR5 variations by determining C3b binding, and analyzing the FHR- 5 serum levels in carrier patients. Furthermore, we analyzed the clinical outcome according to baseline FHR-5 levels and CFHR5 variations. Finally, we explored the connection of FHR-5 levels and CFHR5 variations with the recently described clinically relevant clusters in MPGN $(4,18,36)$.

\section{Results}

\section{Baseline characteristics of the patients}

120 patients with diagnosis of IC-MPGN/C3G and 85 healthy individuals were enrolled in the study. Forty-one patients had C3GN, 12 had DDD and 67 had ICMPGN. There was no difference between patients' and controls' groups in regard to gender and age. C3, C4, AP and classical pathway (CP) activity were decreased in patients with IC-MPGN/C3G (Table 1). Detailed descriptive characteristics of the patients was reported previously (4). There was no difference 
between the different histology-based groups regarding clinical characteristics such as proteinuria, hematuria, renal impairment/failure, triggering event or familiarity. There was a significant, weak negative correlation between patients' FHR-5 levels and eGFR at time of diagnosis $(p=0.0084, r=-0.24)$. 
Table 1

Clinical characteristics of patients with C3G/IC-MPGN

\begin{tabular}{|c|c|c|c|c|c|c|}
\hline & $\begin{array}{l}\text { C3GN } \\
n=41\end{array}$ & $\begin{array}{l}\text { DDD } \\
n=12\end{array}$ & $\begin{array}{l}\text { IC-MPGN } \\
n=67\end{array}$ & $\begin{array}{l}\text { total } \\
n=120\end{array}$ & $\begin{array}{l}\text { Healthy control } \\
n=85\end{array}$ & $p^{*}$ \\
\hline Sex $\%$ men & $22(53.6)$ & $3(25)$ & $43(64.2)$ & $68(56.6)$ & $39(45.9)$ & 0.156 \\
\hline Age at diagnosis, year & $22(15-38)$ & $22(16-42)$ & $19(11-41)$ & $22(13-40)$ & $31(25-36)$ & 0.06 \\
\hline \multicolumn{7}{|l|}{ Clinical data } \\
\hline Non-visible hematuria, present & $25(61)$ & $8(66.6)$ & $38(56.7)$ & $71(61.2)$ & & \\
\hline Visible hematuria, present & $9(22)$ & $2(16.6)$ & $12(18)$ & $23(19.8)$ & & \\
\hline Nephrotic syndrome, present & $19(46.3)$ & $9(75)$ & $33(29.3)$ & $61(52.1)$ & & \\
\hline Renal impairment, present & $14(34.1)$ & $5(41.6)$ & $26(38.8)$ & $45(38.4)$ & & \\
\hline Renal failure, present & $5(12.2)$ & $1(8.3)$ & $6(8.9)$ & $12(10.2)$ & & \\
\hline Trigger, present & $8(19.5)$ & $3(25)$ & $10(15)$ & $21(17.5)$ & & \\
\hline Familiarity, present & $6(14.6)$ & $0(0)$ & $5(7.5)$ & $11(9.1)$ & & \\
\hline \multicolumn{7}{|l|}{ Complement data } \\
\hline Serum C3, g/L & $\begin{array}{l}0.68(0.27- \\
1.06)\end{array}$ & $\begin{array}{l}0.49(0.25- \\
0.87)\end{array}$ & $0.7(0.48-0.99)$ & $0.69(0.3-1)$ & $1.2(1.1-1.4)$ & $<0.0001$ \\
\hline Serum C4, g/L & $0.28(0.2-0.39)$ & $\begin{array}{l}0.21(0.16- \\
0.37)\end{array}$ & $\begin{array}{l}0.21(0.12- \\
0.25)\end{array}$ & $\begin{array}{l}0.22(0.16- \\
0.31)\end{array}$ & $\begin{array}{l}0.32(0.27- \\
0.37)\end{array}$ & $<0.0001$ \\
\hline Classical pathway activity, $\mathrm{CH} 50 / \mathrm{mL}$ & $38(19-62)$ & $47(23-57)$ & $46(30-60)$ & $46(26-60)$ & $64(56-72)$ & $<0.0001$ \\
\hline Alternative pathway activity, \% & $38(1-78)$ & $4(0.3-66)^{1}$ & $70(13-95)$ & $58(1-86)$ & $91(77-104)$ & $<0.0001$ \\
\hline Decreased C3 & $21(51.2)$ & $10(83.8)$ & $37(55.2)$ & $68(56.6)$ & $0(0)$ & $<0.0001$ \\
\hline Decreased C3 with normal C4 & $18(43.9)$ & $10(83.8)$ & $25(37.3)$ & $53(44.2)$ & $0(0)$ & $<0.0001$ \\
\hline Serum FHR-5, mg/L & $1.8(1.5-2.6)$ & $1.6(1.4-2)$ & $1.8(1.3-2.2)$ & $1.8(1.4-2.3)$ & $2.1(1.8-2.5)$ & 0.004 \\
\hline sC5b-9, ng/ml & $429(277-809)$ & $453(248-970)$ & $376(248-658)$ & $407(256-719)$ & & \\
\hline Elevated sC5b-9 & $28(75.6)$ & $7(77.7)$ & $45(75)$ & $80(75.4)$ & & \\
\hline $\mathrm{C} 1 \mathrm{q}, \mathrm{mg} / \mathrm{L}$ & $108(90-130)$ & $95(83-107)$ & $101(69-123)$ & $104(83-123.75)$ & & \\
\hline Factor $\mathrm{H}, \mathrm{mg} / \mathrm{L}$ & $528(470-697)$ & $715(589-903)$ & $495(324-700)$ & $534(381-715)$ & & \\
\hline Factor I, \% & $93(79-112)$ & $87(78-98)$ & $90(74-1110)$ & $91(78-109)$ & & \\
\hline Factor B, \% & $90(72-106)$ & $88(69-124)$ & $91(72-106)$ & $86(67-103)$ & & \\
\hline Factor $D, \mu \mathrm{g} / \mathrm{mL}$ & $1.9(0.7-4.4)$ & $2.8(0.8-4)$ & $2.4(0.95-3.6)$ & $2.31(0.9-3.94)$ & & \\
\hline C3a, ng/mL & $160(70-259)$ & $221(59-259)$ & $125(86-183)$ & $132(79-208)$ & & \\
\hline $\mathrm{Bb}, \mu \mathrm{g} / \mathrm{mL}$ & $1.57(1.12-2.6)$ & $1.7(0.05-3.7)$ & $1.4(0.9-2)$ & $\begin{array}{l}1.49(0.99- \\
2.28)\end{array}$ & & \\
\hline $\mathrm{C} 4 \mathrm{~d}, \mathrm{ng} / \mathrm{mL}$ & $6.2(2.9-8.8)$ & $6.1(3.3-9.4)$ & $4.1(3-8.8)$ & $5.19(3.1-8.9)$ & & \\
\hline C3NeF, present & $7(17.1)$ & $5(41.6)$ & $15(22.4)$ & $27(22.5)$ & & \\
\hline C4NeF, present & $7(17.5)$ & $1(8.3)$ & $9(13.4)$ & $17(14.2)$ & & \\
\hline anti-Factor $\mathrm{H}$, present & $4(10)$ & $0(0)$ & $3(4.5)$ & $7(5.9)$ & & \\
\hline anti-C1q, present & $5(12.8)$ & $1(8.3)$ & $9(14.3)$ & $15(13.4)$ & & \\
\hline anti-C3, present & $2(5.4)$ & $1(8.3)$ & $2(3)$ & $5(4.3)$ & & \\
\hline
\end{tabular}

Data presented are: number (\%) or median (interquartile ranges).

* group comparisons were made with Mann-Whitney U test between "total" and "controls"

** LPVs were detected in the following genes: $C F H, C F I, C F B, C 3, C D 46, T H B D$. Previously identified and functionally characterized missense, as well as nonsense and splice site mutations were categorized as LPV. Novel missense variations were regarded as LPVs if their minor allele frequency was $<1 \%$ in the 1000Genomes Project phase 3 (http://browser.1000genomes.org/index.html) or in gnomAD (https://gnomad.broadinstitute.org/).

Reference ranges: C3: 0.9-1.8 g/L; C4: 0.15-0.55 g/L; CH50: 48-103 CH50/ml; AP: 70-105\%; Factor H: 250-880 mg/L; Factor I: 70-130\%; Factor B: 70$130 \%$ 


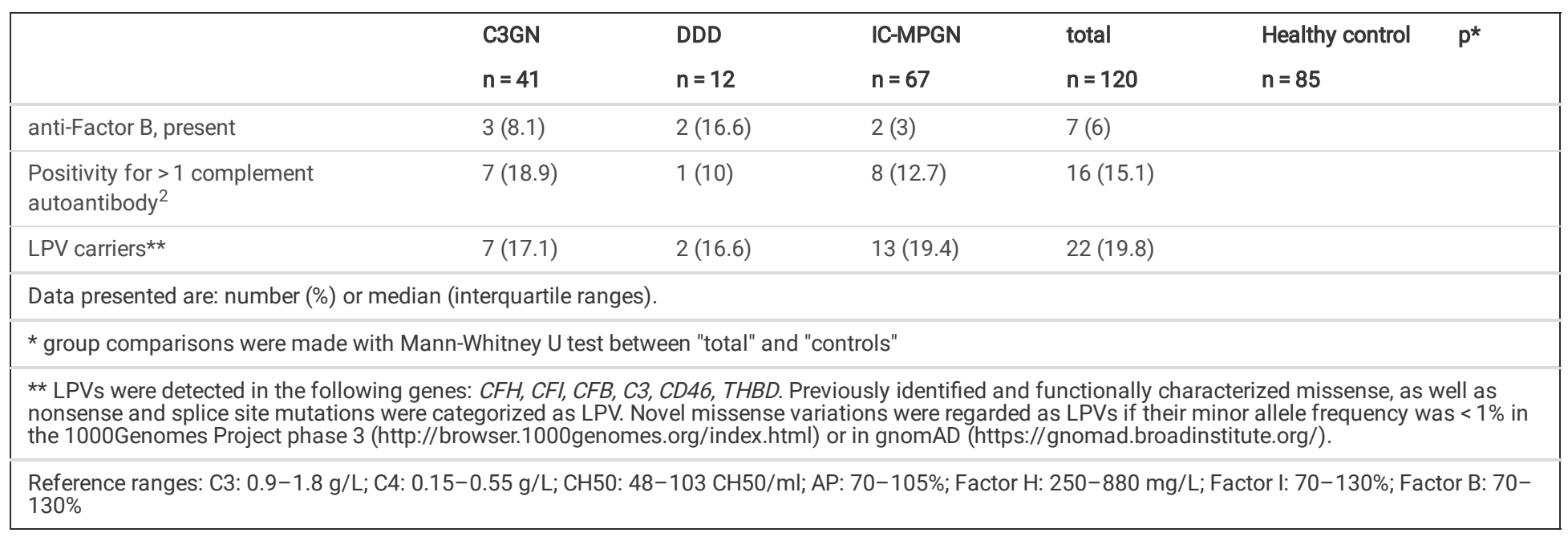


Table 2

A. Variations with unknown significance and likely pathogenic variations affecting $C$

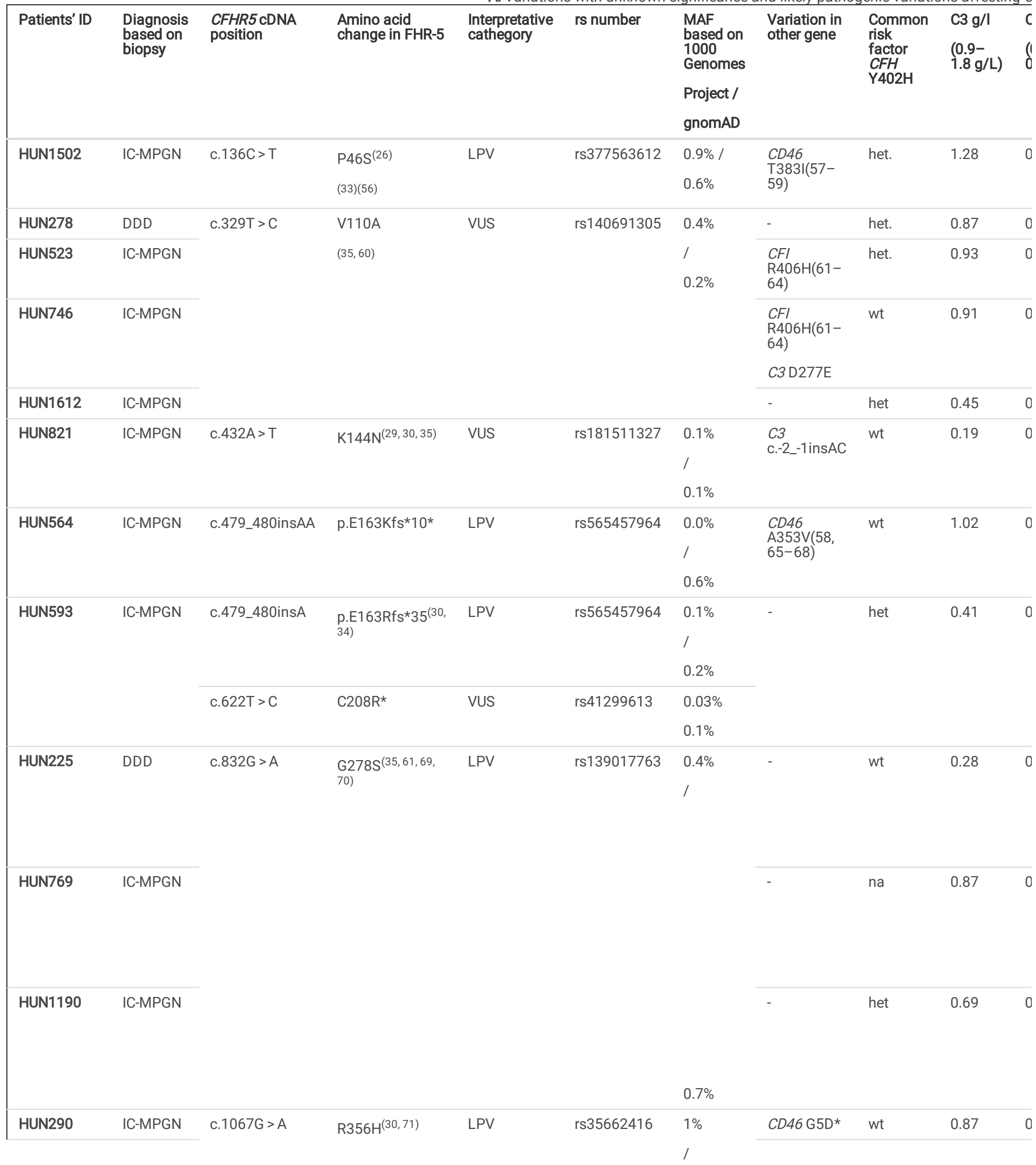

Those missense, nonsense or splice site mutations that were previously identified and functionally characterized were categorized as likely pathogenic variar $<1 \%$ in 1000Genomes Project phase 3 (http://browser.1000genomes.org/index.html)http://www.internationalgenome.org/) or in gnomAD (https://gnomad.b

wt: wild-type; het: heterozygous

LPV: likely pathogen variants; functional studies raise the possible pathogenic effect

VUS: variation with unknown significance 


\begin{tabular}{|c|c|c|c|c|c|c|c|c|c|c|}
\hline Patients' ID & $\begin{array}{l}\text { Diagnosis } \\
\text { based on } \\
\text { biopsy }\end{array}$ & $\begin{array}{l}\text { CFHR5 CDNA } \\
\text { position }\end{array}$ & $\begin{array}{l}\text { Amino acid } \\
\text { change in FHR-5 }\end{array}$ & $\begin{array}{l}\text { Interpretative } \\
\text { cathegory }\end{array}$ & rs number & $\begin{array}{l}\text { MAF } \\
\text { based on } \\
1000 \\
\text { Genomes } \\
\text { Project / } \\
\text { gnomAD }\end{array}$ & $\begin{array}{l}\text { Variation in } \\
\text { other gene }\end{array}$ & $\begin{array}{l}\text { Common } \\
\text { risk } \\
\text { factor } \\
\text { CFH } \\
\text { Y402H }\end{array}$ & $\begin{array}{l}\mathrm{C} \mathrm{g} / \mathrm{l} \\
(0.9- \\
1.8 \mathrm{~g} / \mathrm{L})\end{array}$ & c \\
\hline HUN1325 & C3GN & & & & & $1.6 \%$ & - & wt & 1.24 & 0 \\
\hline \multirow[t]{3}{*}{ HUN2446 } & C3GN & c. $136 \mathrm{C}>\mathrm{T}$ & $\begin{array}{l}\text { P46S }{ }^{(26)} \\
(33(56)\end{array}$ & LPV & rs377563612 & $\begin{array}{l}0.9 \% \\
/ \\
0.6 \%\end{array}$ & - & wt & 0.24 & 0 \\
\hline & & c.479_480insA & $\begin{array}{l}\text { p.E163Rfs } * 35^{(30} \\
\text { 34) }\end{array}$ & LPV & rs565457964 & $\begin{array}{l}0.1 \% \\
/ \\
0.2 \%\end{array}$ & & & & \\
\hline & & c. $622 \mathrm{~T}>\mathrm{C}$ & $\mathrm{C} 208 \mathrm{R}^{*}$ & VUS & rs41299613 & $\begin{array}{l}0.03 \% \\
0.1 \%\end{array}$ & & & & \\
\hline $\begin{array}{l}\text { Total, } \\
\text { median } \\
\text { (interquartile } \\
\text { range) }\end{array}$ & - & - & - & & - & - & - & & $\begin{array}{l}0.87 \\
(0.42- \\
0.93-\end{array}$ & 0 \\
\hline
\end{tabular}

Those missense, nonsense or splice site mutations that were previously identified and functionally characterized were categorized as likely pathogenic variar $<1 \%$ in 1000 Genomes Project phase 3 (http://browser.1000genomes.org/index.html)http://www.internationalgenome.org/) or in gnomAD (https://gnomad.b

wt: wild-type; het: heterozygous

LPV: likely pathogen variants; functional studies raise the possible pathogenic effect

VUS: variation with unknown significance

Table 2

B. In silico predictions for the identified CFHR5 variations

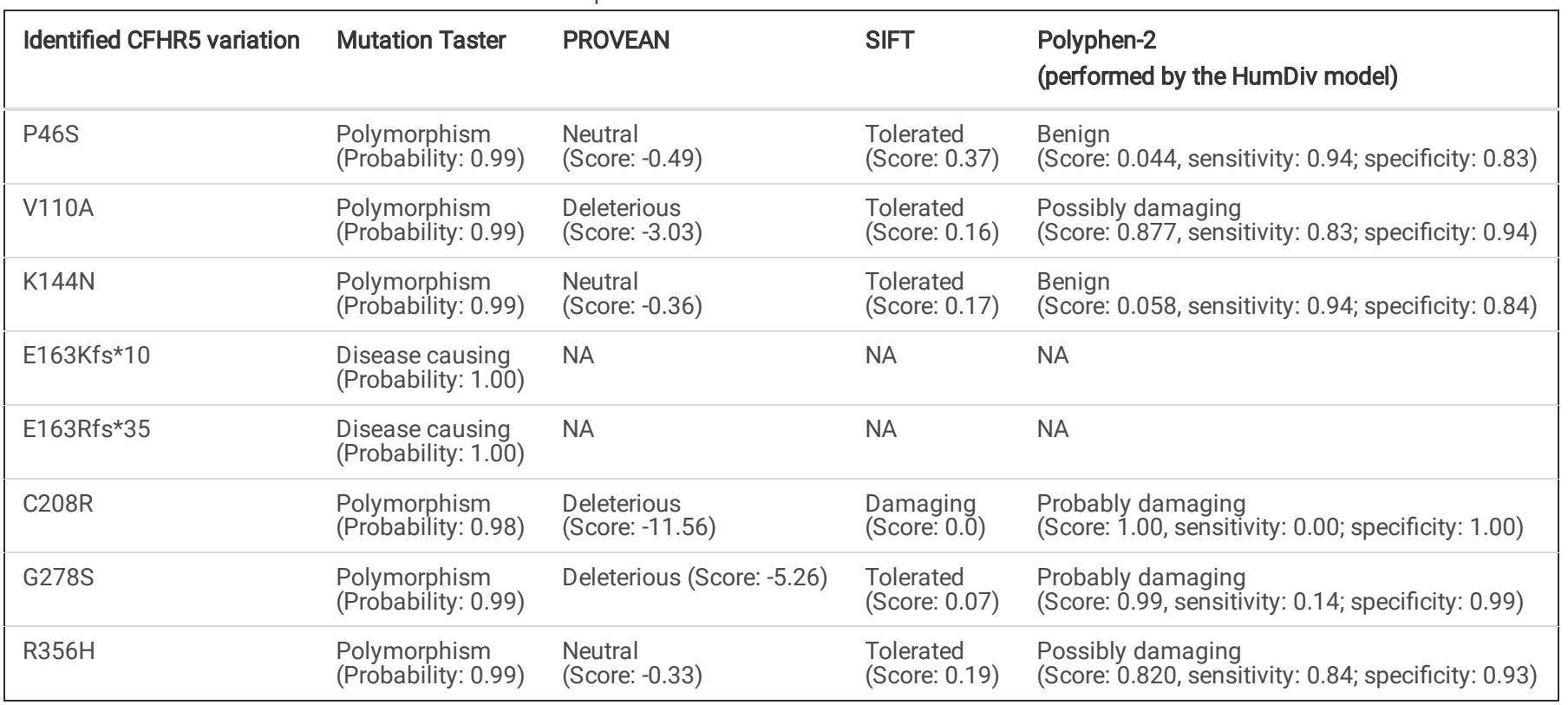

Complement parameters did not show any significant differences except for C4 levels which were lower in patients with IC-MPGN, and AP activity which was the lowest in the DDD group.

Serum FHR-5 levels were significantly lower in patients (median: $1.8 \mathrm{mg} / \mathrm{L}$, interquartile ranges:1.4-2.3) compared to healthy controls (median: $2.1 \mathrm{mg} / \mathrm{L}$, interquartile ranges:1.8-2.5) ( $(=0.004)$ (Table 1), and there was no difference between the various histology-based groups. The specificity of the FHR-5 ELISA was confirmed by western blot (WB) showing that the monoclonal anti-FHR- 5 antibody used as capture antibody did not detect FH or any FHR other than FHR5, and it recognizes FHR-5 ${ }_{\text {WT }}$, FHR-5 $5_{\text {G278S }}$, and FHR-5 ${ }_{\text {R356H }}$ (Fig. 1 and data not shown). 
CFHR5 genetic analysis was performed in 111 patients. Altogether 8 different, heterozygous CFHR5 variations including 2 frame-shift mutations (c.479_480insAA; c.479_480insA) and 6 missense variations (P46S, V110A, K144N, C208R, G278S, R356H) were identified by Sanger-sequencing in 14 patients.

The detailed evaluation and interpretation of the CFHR5 variations are presented in Table $2 \mathrm{~A}$. The in silico predictions of the variations are presented in Table 2B.

Variations in complement genes (CFH, CFI, CD46, CFB, C3, THBD) and complement autoantibodies (C3NeF, C4NeF, anti-C1q, anti-FH, anti-C3, anti-Factor B) were also studied, and for 7 patients with CFHR5 variations (HUN225, HUN593, HUN769, HUN1190, HUN1325, HUN1612, HUN2446) we did not find any additional etiological components in the examined factors causative for AP dysregulation. Among the patients carrying CFHR5 variations, 6 were

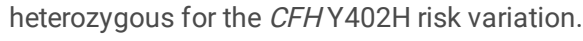

Remarkably, the identified missense and frame-shift CFHR5 variations affect the short consensus repeat (SCR) domains 1-6 in the FHR-5 protein (Fig. 2). We consider 5 variations likely pathogenic, because of 1) variation was previously reported in C3G patients and/or is a recognized pathogenic factor of the disease (p.E163Kfs*10, p.E163Rfs*35) or based on literature data (24) showing segregation with the disease (in case of P46S, carried by HUN1502 and HUN2446) or because 2) results of the functional analysis (for G278S and R356H see below, observed in patients HUN225, HUN290, HUN769, HUN1190, HUN1325) (Table 2A).

In patient HUN593 carrying both a missense and a frame-shift CFHR5 variation (C208R, c.479_480insA), the serum level of FHR-5 was not markedly decreased $(1.88 \mathrm{mg} / \mathrm{L})$ contrary to what was expected, and we further investigated this sample on WB, where FHR-5 protein was detected in the expected position (Fig. 3) with comparable intensity to that of wild-type FHR-5, confirming the observation done by ELISA (Fig. 2). The possible explanation is that the two identified CFHR5 variations are located on the same allele and thus the other allele is intact (unfortunately, we have not received samples from the parents, therefore we cannot confirm this hypothesis).

In patient HUN2446 three different CFHR5 variations were identified including one frame-shift and two missense variations (P46S, C208R, c.479_480insA). As it was expected, the serum level of FHR-5 was decreased ( $0.47 \mathrm{mg} / \mathrm{L})$. The patient's mother carries two CFHR5 variations (C208R, C.479_480insA) whereas the father is heterozygous for CFHR5 P46S. Both of the parents are healthy (Fig. 4). Interestingly, the patient's mother did not have any signs of renal disease whereas another patient carrying the same two CFHR5 variations (HUN593) is diagnosed with IC-MPGN. HUN593 also had anti-Factor B antibody and is heterozygous for $\mathrm{CFHY} 402 \mathrm{H}$ that are additional risk factors for the disease.

FHR-5 serum levels were similarly low in patients, irrespective of CFHR5 variations, when compared to controls (Fig. 5). There was no remarkable association of the FHR-5 protein concentrations with the localization of the variations in various FHR-5 domains (Fig. 2).

\section{Functional characterization of CFHR5 variations}

To determine whether CFHR5 variations influence FHR-5 functions, we measured serum FHR-5 binding to C3b. FHR-5 binding was significantly lower in patients carrying the G278S mutation compared with those expressing only wild-type FHR-5, carrying mutations in the dimerization domains SCR1-2 (P46S, V110A, K144N) or carrying the R356H mutation in the predicted ligand binding region SCR5-7 (Fig. 6A). To confirm that the reduced binding is due to the mutations and not to the differences in FHR-5 serum level, recombinant FHR-5 mutants harbouring serine in the 278 amino acid position (FHR- $5_{\mathrm{G} 278 \mathrm{~S}}$ ) or histidine in the 356 amino acid position (FHR- $5_{\mathrm{R} 356 \mathrm{H}}$ ), and the wild-type protein were produced. In ELISA measurements all three variants bound dosedependently to $\mathrm{C} 3 \mathrm{~b}, \mathrm{FHR}-5_{\mathrm{G} 278 \mathrm{~S}}$ showing significantly weaker binding (Fig. $6 \mathrm{~B}$ ). This interaction was also analyzed by SPR method. The $\mathrm{K}_{\mathrm{D}}$ values calculated for the C3b-FHR-5 interactions are in line with the ELISA results $\left(2.05 \times 10^{5} \mathrm{M}\right.$ for C3b-FHR- $5_{\mathrm{G} 278 \mathrm{~S}}$ versus $5.26 \times 10^{-6} \mathrm{M}$ and $5.60 \times 10^{-6} \mathrm{M}$ for C3b-FHR-5 $\mathrm{WT}$ and $\mathrm{C} 3 \mathrm{~b}-\mathrm{FHR}-5_{\mathrm{R} 356 \mathrm{H}}$ ), since $\mathrm{FHR}-5_{\mathrm{G} 278 \mathrm{~S}}$ has reduced binding to $\mathrm{C} 3 \mathrm{~b}$, while FHR- $5_{\mathrm{R} 356 \mathrm{H}}$ binds to $\mathrm{C} 3 \mathrm{~b}$ with similar affinity as the wild-type protein. In details, C3b showed slower association to both FHR- $5_{\mathrm{G} 278 \mathrm{~S}}$ and FHR- $5_{\mathrm{R} 356 \mathrm{H}}$ (see decreased ka values compared to that of FHR- $5_{\mathrm{WT}}$ ). The dissociation was faster in case of FHR- $5_{\mathrm{G} 278 \mathrm{~S}}$, and slower in case of FHR- $5_{\mathrm{R} 356 \mathrm{H}}$ compared to FHR-5 $5_{\mathrm{WT}}$. These differences in association and dissociation result in a weaker interaction with C3b in case of FHR-5 $5_{\mathrm{G} 278 \mathrm{~S}}$ (Fig. 6C). The observed weaker C3b-binding capacity of the FHR- $5_{\mathrm{G} 278 \mathrm{~S}}$ variant may be in line with a more appropriate regulation achieved by FH, and remarkably, those three patients (HUN225, HUN769, HUN1190) carrying the CFHR5 G278S variant seem to have better renal outcome, as none of them progressed to end-stage renal disease (ESRD).

\section{Laboratory, Clinical Associations And Prognostic Significance Of Fhr-5 Levels}

Next, we aimed to analyze the potential association of serum FHR-5 levels and clinical outcome. In order to have a homogeneous group of MPGN patients with wild-type FHR-5, we stratified the patients carrying CFHR5 variations into a separate group, to facilitate better understanding of the association and relevance of FHR-5 protein levels with clinical features, development of ESRD. Based on the successfully followed patients' ( $n=101$ among whom 93 had genetic analysis) FHR-5 levels and development of ESRD, groups with high or low FHR-5 concentrations were made, where the cut-off point (1.565 mg/L) was defined by ROC-analysis. Patient characteristics according to high (median: 2.16 mg/L; 1.87-2.85) or low (median: 1.34 mg/L; 1.12-1.46) FHR-5 serum levels are shown in Table 3, patients with CFHR5 variations are presented as a reference group. Seventeen out of the 92 patients (median: $1.53 \mathrm{years}$; min-max: 0.05 6 years) progressed or stayed in ESRD (Table 4). None of the patients with CFHR5 variation(s) progressed to ESRD during follow-up (Table 3 and Fig. 7). Fifteen patients with high FHR-5 levels (ESRD rate: 0.38 event/patient/year; median follow-up: 4.5 years, min-max: 0.05-6) progressed to ESRD whereas the same was observed only for 2 patients with low FHR-5 (ESRD rate: 0.04 event/patient/year; median follow-up: 1.98 years min-max: 0.11-6) concentrations. Patients with higher FHR- 5 levels had the worst renal survival, when compared to patients with low FHR- 5 concentrations ( $p=0.034)$, or when the three groups were analyzed together $(p=0.016)$ (Fig. 7). 
Table 3

Presenting clinical and laboratory characteristics of patients with or without CFHR5 variations, stratified according to FHR- 5 serum levels

\begin{tabular}{|c|c|c|c|c|}
\hline & \multirow{3}{*}{$\begin{array}{l}\text { Patients with CFHR5 variations* } \\
n=13\end{array}$} & \multicolumn{2}{|c|}{ Patients without $C F H R 5$ variation } & \multirow[t]{3}{*}{ p value** } \\
\hline & & serum FHR-5 $<1.565$ mg/L & serum FHR-5 > 1.565 mg/L & \\
\hline & & $\mathrm{n}=\mathbf{2 8}$ & $\mathrm{n}=52$ & \\
\hline Sex \% men & $7(53.8)$ & $13(46.4)$ & $33(63.4)$ & 0.14 \\
\hline Age at diagnosis & $17(8-29)$ & $16(11-26)$ & $31(15-47)$ & 0.012 \\
\hline Non-visible hematuria, present & $7(53.8)$ & $19(67.8)$ & $32(61.5)$ & 0.57 \\
\hline Visible hematuria, present & $3(23)$ & $5(17.8)$ & $10(19.6)$ & 0.77 \\
\hline Nephrotic syndrome, present & $8(61.5)$ & $12(42.8)$ & $28(54.9)$ & 0.3 \\
\hline Renal impairment, present & $6(46.2)$ & $8(29.6)$ & $23(45)$ & 0.03 \\
\hline Acute renal failure, present & $0(0)$ & $2(7.4)$ & $7(13.7)$ & 0.48 \\
\hline Sclerosis on light microscopy (\%) & $0(0-5.2)$ & $6.7(0-17.8)$ & $14.2(0-44.4)$ & 0.17 \\
\hline Crescent on light microscopy (\%) & $0(0-5.8)$ & $0(0-6)$ & $0(0-17.6)$ & 0.21 \\
\hline ESRD during follow-up period, present & $0(0)$ & $2(7.1)$ & $15(28.8)$ & 0.02 \\
\hline Serum C3, g/L & $0.64(0.24-0.78)$ & $0.37(0.21-0.98)$ & $0.8(0.3-1)$ & 0.21 \\
\hline Serum C4, g/L & $0.18(0.10-0.25)$ & $0.21(0.13-0.26)$ & $0.24(0.2-0.35)$ & 0.02 \\
\hline sC5b-9, ng/mL & $534(375-751)$ & $517(273-1277)$ & $349(244-574)$ & 0.09 \\
\hline Decreased C3, present & $9(69.2)$ & $19(67.8)$ & $25(48)$ & 0.08 \\
\hline Decreased C3 with normal C4, present & $4(30.8)$ & $5(17.8)$ & $3(5.7)$ & 0.12 \\
\hline Elevated sC5b-9, present & $11(84.6)$ & $19(79.2)$ & $36(72)$ & 0.58 \\
\hline Classical pathway activity, $\mathrm{CH} 50 / \mathrm{mL}$ & $37(12-49)$ & $35(3.7-60.7)$ & $45.5(29-60)$ & 0.17 \\
\hline Alternative pathway activity, \% & $27(0,75-67)$ & $8(1-81)$ & $61(6-88)$ & 0.1 \\
\hline Serum FHR-5, mg/L & $1.54(0.92-1.88)$ & $1.34(1.12-1.46)$ & $2.16(1.87-2.85)$ & $<0.0001$ \\
\hline \multicolumn{5}{|c|}{ *Patients with $C F H R 5$ variations are shown for reference. } \\
\hline
\end{tabular}


Table 4

Clinical characteristics of patients with or without ESRD development during follow-up period, and without CFHR5 variation at time of diagnosis

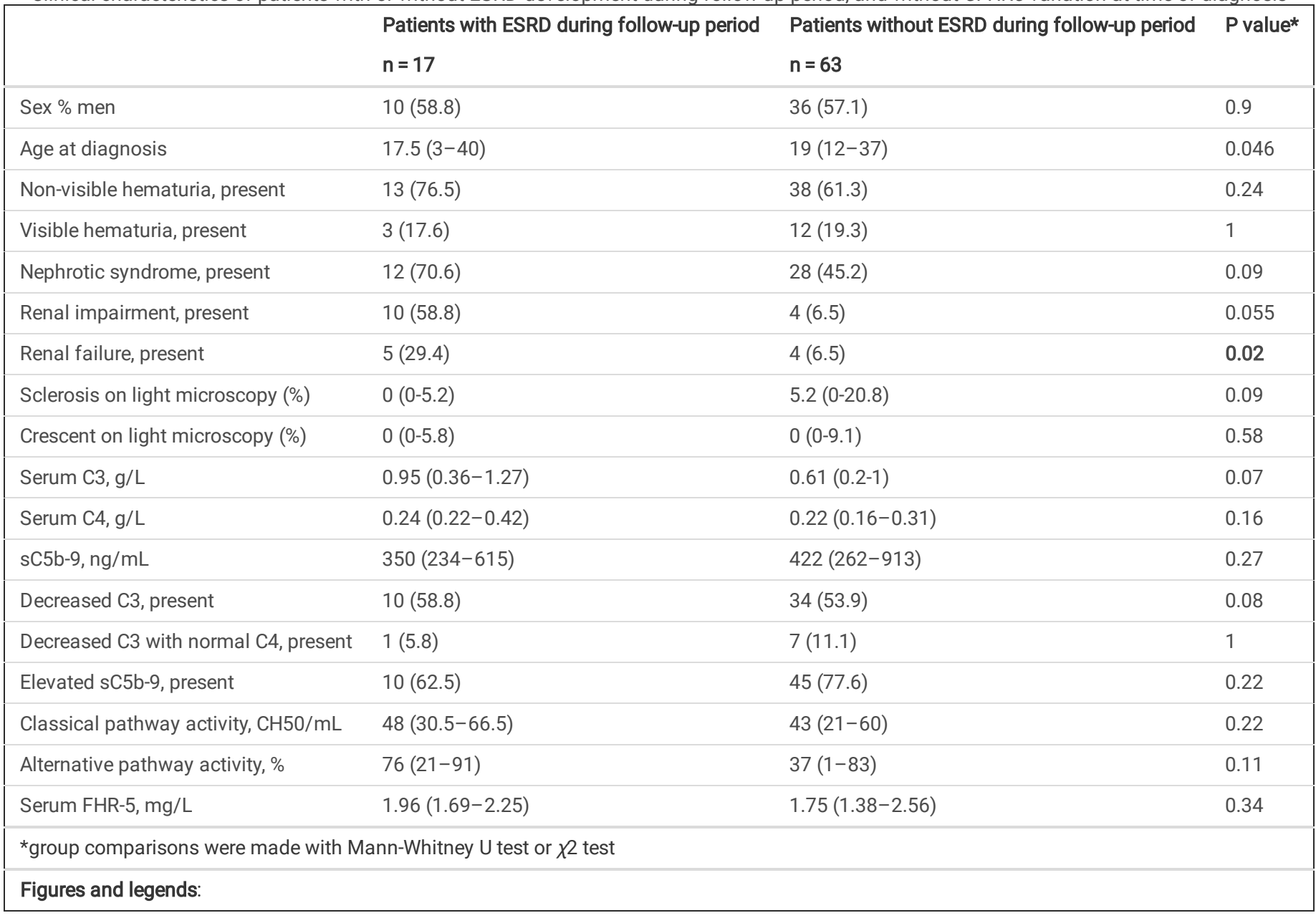

We have also examined the distribution of serum FHR-5 levels across the previously described clusters $(4,18)$ and observed a clear association: patients in cluster 3 (median:2.35 mg/L, IQ-range 1.77-3.16) and cluster 4 (median:1.96 mg/L, IQ-range 1.48-2.23) had significantly higher FHR-5 levels when compared to cluster $1(1.47,1.25-1.98, p<0.05$, Dunn's post hoc test, $p=0.0003$, ANOVA, Fig. 8). The presence of patients with variations with unknown significance (VUS) or likely pathogenic variations (LPV) in CFHR5 was the highest in cluster $1(10 / 49 ; 20.4 \%)$ when compared to the other clusters $(4 / 58 ; 6.9 \%)(p=0.047$, $\chi^{2}$-test, Fig. 8), whereas development of ESRD during follow-up occurred less frequently among patients in cluster 1 (2/43; $\left.4.8 \%\right)$ compared to patients in cluster $3(5 / 17 ; 29.4 \% ; p=0.016)$ and cluster $4(9 / 33 ; 27.3 \% ; p=0.007)$.

\section{Discussion}

In this study, we have examined the FHR-5 serum levels and the CFHR5 genetic variations in a large group of IC-MPGN/C3G patients and in healthy controls. Furthermore, we identified 5 different CFHR5 variations that are considered to have a likely pathogenic effect, either as 1 ) confirmed by our functional studies (in case of $\mathrm{G} 278 \mathrm{~S}$ and $\mathrm{R} 356 \mathrm{H}$ ), or 2) the variation was previously published in C3G patients and/or is a recognized pathogenic factor of C3G (p.E163Kfs*10, p.E163Rfs*35) or 3) based on literature data (24) showing segregation with the disease (in case of P46S).

To the best of our knowledge, this is the first observational study describing FHR-5 levels together with the presence of likely pathogenic CFHR5 variations as well as clinical and laboratory data in a reasonably large group of IC-MPGN/C3G patients. In this cohort, $11.7 \%$ of the patients carry CFHR5 variations, representing 8 different missense/frame-shift variations.

Similarly to C3, C4, CP and AP activity, FHR-5 levels were lower in patients than in healthy controls. Patients with low FHR-5 levels had superior renal survival compared to patients with higher FHR- 5 levels, and this association was independent of CFHR 5 variation carrier status. Interestingly, FHR- 5 levels and CFHR 5 variations showed clear association with clusters of the patients: patients with hypocomplementemia, low FHR-5 levels, presence of $C F H R 5$ variations and good renal outcome fall into cluster 1, whereas patients in cluster 3 and 4 had higher levels of FHR- 5 with worse renal outcome.

Genetic alteration of CFHR5 as a pathogenic factor was first described by Gale et al (27), where they showed that internal duplication of exons 2-3 of CFHR5 leads to familial C3G termed CFHR5-nephropathy. FHR-5 was reported to be colocalized in renal tissue together with other complement containing immunedeposits $(19,37)$, although the pathogenic role of this protein was not fully understood and it was hypothesized that it may have a physiological role in complement activation in the kidney but large observational studies are missing. In a large American cohort $(\mathrm{n}=104)$ only $C F H R 5$ variations were examined without further comparison with serum levels and clinical data. (35) The identified missense/frame-shift CFHR5 variations in our IC-MPGN/C3G patients affect the SCR1-6 domains of the FHR-5 protein. FHR-5 was shown to form only homodimers in plasma (38) which is mediated via SCR1-SCR2 (22), that were

Page $12 / 26$ 
affected by 3 different substitutions (P46S, K144N and V110A) in our cohort. These variations may affect the ligand binding (such as properdin (39)) and the dimerization ability of FHR-5, but functional studies are needed to confirm this hypothesis. We also identified 2 different frame-shift mutations that are caused by the insertion of one or two adenine bases (E163Rfs*35; E163Kfs*10), affecting the SCR3 domain that has unknown function. Interestingly, in a previous case report, the E163Rfs*35 mutation occurred along with low FHR-5 concentration in one patient suffering from glomerulonephritis following streptococcal infection but not in unaffected carriers (34). In our cohort the FHR-5 levels of these three patients with frame-shift mutations were not decreased when analysed by ELISA and WB methods. This could be explained by the fact that these patients are heterozygous and the intact allele can produce the detected protein.

The remaining 3 missense variations (G278S, R356H and the novel C208R) affected the SCR4-6 domains that are partly responsible for the binding of Creactive protein $(21)$, heparin (SCR5-7 $(21,40)$ ), laminin (SCR5-7 (40)) and necrotic human endothelial cells (SCR5-7 (40)) based on previous studies (and the binding of pentraxin-3 to SCR5-7 was also hypothesized (23)). Of these, the C208R variation occurred together with the E163Kfs*35 mutation in one IC-MPGN patient (and it was also observed in two aHUS patients of our registry, unpublished results) and in one C3GN patient with the P46S variation also. Three patients carrying the G278S variation had variable levels of FHR- 5 and both patients carrying the R356H variation had FHR- 5 concentration below the median level observed in controls. We could not find any additional etiological factors in the examined genes and complement autoantibodies except for CFHR5 variations (resulting in $\mathrm{P} 46 \mathrm{~S} / \mathrm{E} 163 \mathrm{Rfs}^{*} 35 / \mathrm{C} 208 \mathrm{R} / \mathrm{G} 278 \mathrm{~S} / \mathrm{R} 356 \mathrm{H}$ ) in 7 patients. By analyzing recombinant proteins harboring these mutations, we found the FHR- $5_{\text {G278S }}$ variant has decreased C3b binding ability (Fig. 3). Since FHR-5 was shown to compete with FH for ligand binding, among others for C3b, the reduced competition capacity of FHR-5 might explain our observation that patients carrying this variant tend to have better renal outcome (none of them progressed to ESRD during the median 1.36 year-long follow-up period (min: 0.35 year; max: 5.12 years)), as a more appropriate regulation is achieved by FH. Nevertheless, C3b is only one of the common FH/FHR ligands, the function of FHR- 5 and the effect of mutations should be further investigated. In an other perspective, interaction between FHR proteins and the extracellular matrix components can also modify the regulator activity of FHR proteins. The interactions between FHR-5 protein and the surface components such as glycosaminoglycans may also play a role in complement dysregulation (25). As C3G is considered as a polygenic disease, variations in CFHR5 are supposed to play a disease-modifying role in C3G predisposition and disease development. In recent years, two studies performing CFHR5 sequencing in aHUS patients ( $\mathrm{n}=54$ and $\mathrm{n}=65$ ) were published which reported some novel $C F H R 5$ variations, including two alterations coding for K144N and R356H that were observed in our patients as well $(29,30)$. On the other hand, a large study was reported including 500 IgAN patients (31) carrying several CFHR5 variations but none of these mutations was observed in our patients. FHR-5 levels were higher in IgAN patients than in control subjects in several studies $(32,33)$ and higher FHR- 5 concentrations were associated with the progression of IgAN $(32)$. Our study is the first that performed FHR- 5 level measurement in a large IC-MPGN/C3G cohort along with comprehensive analysis of the genetic background and clinical data. FHR-5 levels were significantly lower in patients with or without CFHR5 variations compared to controls, which is in line with the observations of Vernon et al. who found decreased FHR-5 levels in 23 patients with C3GN, with or without CFHR5 alterations, compared to controls (34). Not only FHR-5 but other complement parameters were also lower in patients compared to controls, supporting the idea that increased complement activation and consumption may cause these differences. Infectious trigger is suggested to contribute to the development of C3G (41), and such trigger may represent a key initiating factor for the development of complement dysregulation. Potential contributing factors to the development of such dysregulation are the common allelic variants of regulators and de-regulators (including FHR-5, (34)) which may give rise for the formation of complement targeted autoimmunity during infection. The difficult question of whether C3G is triggered directly by infections or it is a pre-existing lesion that becomes clinically overt during infections, remains unanswered today, but our observation on allelic variants in complement AP deregulator FHR- 5 may shed new light on this issue.

FHR-5 levels showed clear association with renal survival, as survival was better in IC-MGPN/C3G patients with lower FHR- 5 level, than in patients with higher FHR-5 level. This observation is similar to the observation obtained for IgAN patients (32). We do not have a formal explanation for this phenomenon, but our hypothesis is that decreased level/function of deregulator FHR-5 protein allows FH to regulate complement activation more efficiently. If the delicate balance between FH and FHR-5 function could be shifted due to a damaging CFHR5 mutation, the pathogens (of which many have the capacity to interact with FH, (42)) may escape complement action as a result of decreased deregulator activity during disease development. In turn, later in disease course patients having lower deregulator activity, and hence, appropriate regulation by FH, may have a better renal survival. In addition, patients with lower baseline eGFR have higher FHR-5 serum levels which also support this hypothesis. Remarkably, in this cohort no ESRD developed during follow-up in patients with CFHR5 variations.

All these observations support the possibility that FHR-5, and thus carriage of CFHR5 variations, may play a role in the pathogenesis of IC-MPGN/C3G but these are not the only disease-causing factors. Our hypothesis is that the observed CFHR5 variations may be additional fine-tuning factors in disease pathogenesis and progression. In many cases autoantibodies against different complement components occur together with genetic variations or risk polymorphism, however, we have not identified a clear association between them in our previous studies $(4,36)$. Recently, a large-scale whole-genome sequencing study did not find a clear relationship between the identified rare variations and C3G, however, a strong association was identified between primary MPGN and a haplotype containing DQA1*05:01; DQB1*02:01 and DRB1*03:01. Of these, DQB 1*02:01 and DRB1*03:01 are associated with different autoimmune diseases such as rheumatoid arthritis and membranous nephropathy. These genes are coding components of the MHCII molecule (found on the surface of antigen-presenting cells) which plays an important role in the adaptive immune response and in (auto)antibody production. These results raise the possibility that although genetic variations have a disease-modifying effect, it is the aberrant adaptive immune mechanism, thus autoimmunity that could be the key mechanism in the background of C3G (as shown by the high occurrence of autoantibodies) rather than the genetic abnormalities (43)

We have further analyzed whether CFHR5 variations and serum FHR-5 concentrations are in connection with the recently described (18) and validated clinically meaningful clusters (4). IC-MPGN/C3G patients were clustered based on clinical, histological, complement and genetic data and clear association with disease pathogenesis and renal survival was observed supporting the relevance of the clusters, and our study found that FHR-5 levels were lower in cluster 1 along with higher prevalence of CFHR5 variations. Cluster 1 was also characterized by younger age of onset, higher complement activation with higher prevalence of complement autoantibodies and better renal survival. On the contrary, worst renal survival was observed in clusters 3 and 4 in our study, and patients in cluster 3 and 4 had higher FHR-5 levels. 


\section{Conclusions}

In conclusion, our study is the first to report observational data on CFHR5 variations together with functional characterization, and serum FHR- 5 levels at disease presentation in a large group of IC-MPGN/C3G patients. We observed that 14 patients (11.7\%) were carriers of 8 different CFHR5 variations, among them we considered 5 as pathogenic or likely pathogenic based on functional analysis or detailed evaluation and segregation data from the literature (Table 2A). Low serum FHR-5 concentration at presentation was associated with decreased incidence of ESRD during follow-up. Low serum FHR-5 levels showed clear association with signs of hypocomplementemia and clinically meaningful groups (clusters) of patients. Further studies, including detailed in vitro characterization of the functional effects of the identified CFHR5 variations, are necessary to better understand the role of FHR-5 in the pathogenesis of complement-mediated kidney diseases. These investigations are in progress in our laboratories.

\section{Methods}

\section{Patients and control subjects}

Samples of 206 patients were sent to our Research Laboratory from Central-European clinical centers $(n=34)$ with the suspicion of complement-mediated renal disease for complement investigations, and for them genetic analysis was also carried out. 86 patients were excluded because of alternative diagnosis or secondary MPGN. 120 patients with the diagnosis of IC-MPGN/C3G were enrolled in the study from January 2008 to May 2019.

The clinical, histological and laboratory data were collected from the clinicians and pathologists according to study protocols approved by the Medical Research Council of the Ministry of Human Capacities in Hungary (approval's number:55381-1/2015/EKU).

Biopsy data were collected using standardized questionnaire forms from pathologists $(n=73)$ or extracted from the biopsy descriptions $(n=47)$.

Eighty-five subjects formed the control group (68 adults, 17 children). All of them were referred for routine medical examination and none of them had any known disease at time of blood sampling.

Both the healthy subjects and the patients or their parents gave their written approval - after informed consent - for the analysis in accordance with the Declaration of Helsinki.

\section{Molecular Genetic Analysis}

In 111 patients the whole coding region of the gene encoding FHR-5 (CFHR5; OMIM\# 608593) was screened by direct bidirectional DNA sequencing, as described in the case of further disease-associated genes ( $C F H, C F I, C D 46, T H B D, C F B, C 3)$ that were sequenced also (44). No DNA samples were available from the remaining 9 patients. These genes were not sequenced in the included healthy subjects; instead of that the available public databases (1000Genomes Project, gnomAD) were used to acquire data about allele frequencies in more reliable and larger healthy populations. Primer sequences and PCR conditions are available upon request. Multiplex ligation-dependent probe amplification (MLPA) was performed to study the presence of copy-number alterations in the chromosomal regions of the CFHR1, CFHR2, CFHR3 and CFHR5 genes, with the SALSA MLPA probemix P236-A3 (MRC-Holland, Amsterdam, the Netherlands) following the manufacturer's instructions.

Polymorphic variations are numbered as +1 from the A allele of the ATG translation initiation site. Those missense, nonsense or splice site mutations that were previously identified were categorized as likely pathogenic variations. In order to include every variation and not to miss information, novel variations were also included if they were found with a minor allele frequency of $<1 \%$ in 1000Genomes Project phase 3 (http://browser.1000genomes.org/index.html) or in gnomAD (https://gnomad.broadinstitute.org/). The possible functional effect of novel variations was predicted in silico using the following online prediction tools, such as PolyPhen (version2)(45) (http://genetics.bwh.harvard.edu/pph2/), SIFT(46) (http://siftdna.org/www/Extended SIFT chrcoords submit.html), PROVEAN(47) (http://provean.jcvi.org/genomesubmit.php), Human Splicing Finder (version 3.1, http://www.umd.be/HSF3/) (48) and MutationTaster (49) (http://mutationtaster.org).

\section{Generation Of Recombinant Wild-type And Mutant Fhr-5 Variants}

Coding sequence of wild-type CFHR5 (wtCFHR5) was codon-optimized for insect cell expression system (Integrated DNA Technologies, Inc.) and cloned into the pBSV-8His expression vector(50). Two mutants were amplified from the wtCFHR5-containing vector with mutagenic forward primers introducing the mutations FHR- $5_{\mathrm{G} 278 \mathrm{~S}}$ and FHR-5 $\mathrm{R}_{356 \mathrm{H}}$. Sequences and mutations were confirmed by sequencing. Recombinant proteins were produced in Spodoptera frugiperda ( $\mathrm{Sf9}$ ) cells after co-transfection of the various CFHR5-containing expression vectors with linearized baculovirus DNA (Oxford Expression Technologies Ltd.) and purified from the supernatant by nickel affinity chromatography.

\section{Measurement Of The Interaction Of Fhr-5 With Purified C3b}

To compare the C3b binding ability of FHR- $5_{W T}, F H R-5_{G 278 S}$ and FHR- $5_{R 356 H}$, microtiter plate wells (MaxiSorp, Nunc) were coated with $5 \mu \mathrm{g} / \mathrm{ml} \mathrm{C} 3 \mathrm{~b}$ (Merck). After blocking with $5 \%$ BSA in $0.05 \%$ Tween-20 containing Dulbecco's phosphate buffer saline (DPBS) (Lonza), serial dilutions of recombinant FHR-5 variants were added to the wells for $1 \mathrm{~h}$ at $20^{\circ} \mathrm{C}$. Binding was detected with polyclonal goat anti-human-FHR-5 IgG (Cat. number:AF3845,R\&D Systems) followed by 
HRP-labelled rabbit anti-goat Ig (Dako, Hamburg, Germany). The binding was visualized using 3,3',5,5'-tetramethylbenzidine (TMB) (BioLegend) and the absorbance was measured at $450 / 620 \mathrm{~nm}$.

The interaction of the recombinant FHR-5 variants with C3b was also analyzed by surface plasmon resonance (SPR) method using ProteOn XPR36 equipment (Bio-Rad). Recombinant proteins and ovalbumin (Sigma-Aldrich) as negative control were diluted in $10 \mathrm{mM} \mathrm{Na-acetate} \mathrm{buffer} \mathrm{(pH} \mathrm{4.0)} \mathrm{and} \mathrm{immobilized}$ vertically at a density of 4,200-4,600 RU on GLC biosensor chip by standard amine coupling method. As analyte, serial dilutions of C3b were prepared in DPBS containing $0.005 \%$ Tween- 20 and injected in the horizontal orientation of channels over immobilized recombinant FHR- 5 variants. Measurements were performed at $50 \mu \mathrm{l} / \mathrm{min}$ flow rate, association was followed for $120 \mathrm{~s}$ and the dissociation for $600 \mathrm{~s}$. Data were processed and analyzed with ProteOnManager software. The curves were corrected by subtracting the non-specific binding responses obtained from control, the ovalbumin captured channel. Binding curves were fit to bivalent analyte model and the equilibrium dissociation constants were calculated from the directly estimated association and dissociation rate constants $\left(K_{D}=k_{d} / k_{a}\right)$. The experiment was performed twice on separate GLC biosensor chips.

To measure the C3b binding ability of the native (wild-type or mutant) FHR-5 from serum samples, microtiter plate wells (MaxiSorp, Nunc) were coated with $5 \mu \mathrm{g} / \mathrm{ml}$ C3b fragment (Merck) $\left(\mathrm{ON}, 4^{\circ} \mathrm{C}\right)$. After blocking with DPBS containing $2 \%$ BSA ( $\left.1 \mathrm{~h}, \mathrm{RT}\right)$, serum samples diluted $1: 4$ in DPBS containing $1 \%$ BSA, $0.05 \%$ Tween 20, as well as a dilution series (3.9-250 ng/ml) of recombinant human FHR-5 (R\&D Systems) were applied to the plate ( $\left.1 \mathrm{~h}, 37^{\circ} \mathrm{C}\right)$. Binding was detected with monoclonal mouse anti-human FHR-5 (R\&D Systems) (1 h, RT), followed by HRP-labelled goat anti-mouse IgG (Jackson ImmunoResearch) (1 h, RT). As substrate TMB (BioLegend) was used and the absorbance was measured at $450 / 620 \mathrm{~nm}$.

\section{Elisa For Measuring The Serum Level Of Fhr-5}

FHR-5 serum levels were measured with newly developed in-house ELISA method. Microtiter ELISA plates were coated with $1 \mu \mathrm{g} / \mathrm{mL}$ commercially available monoclonal mouse anti-human-FHR-5 (IgG1, clone\#390513, R\&D Systems) in PBS overnight, followed by blocking with PBS and 2\% BSA the next day. Serum was diluted 1:100 in PBS containing 1\% BSA and 0.05\% Tween-20 and added to the plate for 1 hour at RT. FHR-5 binding was detected as above using polyclonal goat anti-human-FHR-5 IgG (Cat. number: AF3845, R\&D Systems). The concentrations of the samples were determined based on the standard curve of the two-fold dilution series of recombinant human FHR-5 protein (R\&D Systems). Inter-assay and intra-assay variations were determined and appeared to be $11.8 \%$ and $7.8 \%$, respectively.

\section{Western Blot For Detection Of Fhr-5}

Serum proteins from patients and a healthy individual were separated on 10\% SDS-PAGE under non-reducing conditions and blotted onto nitrocellulose membrane. After blotting, the membrane was blocked with $4 \%$ non-fat dried milk, $1 \%$ BSA in PBS solution. Then the membrane was incubated with a polyclonal goat anti-FHR-5 (Cat. number:AF3845, R\&D Systems) or monoclonal mouse anti-FHR-5 antibody (clone\#390513, Cat. number: MAB3845, R\&D Systems) followed by HRP-conjugated secondary antibodies (rabbit anti-goat and goat anti-mouse, respectively; Southern Biotech, Birmingham, USA). Bound antibodies were detected with Clarity Western ECL substrate (Bio-RAD, California, USA).

\section{Determinations Of Complement Parameters}

Samples (serum, EDTA-anticoagulated- and sodium-citrate-anticoagulated plasma) were taken from the antecubital vein, or from a central venous catheter. Cells and supernatants were separated by centrifugation after the sample was taken, and transferred to our laboratory. Separated aliquots were stored at $70{ }^{\circ} \mathrm{C}$ until measurements.

C3, C4 concentrations were measured by turbidimetry (Beckman Coulter, Brea, CA).

AP activation was measured by a commercially available kit (Wieslab AP ELISA KITs, EuroDiagnostica, Malmö, Sweden), according to the manufacturer's instructions.

Total CP activity was measured by a home-made hemolytic titration test based on Mayer's method (51). Radial immunodiffusion was performed to measure the antigenic concentrations of Factor I and Factor B, using specific antibodies (52). Levels of FH, C1q and antibodies against FH, C1q,(52-54) C3 and Factor $B$ were measured with in-house ELISA methods (4) whereas C3NeF and C4NeF titer was determined based on hemolytic method $(4,55)$.

Further complement components, activation markers and split products, such as Factor D, sC5b-9, C3a, Bb and C4d were detected with commercially available ELISA kits (HyCult Complement Factor D, Human, ELISA kitHK343-02; MicroVue C3a-desArgEIA, A032; MicroVue C4d EIA, A008; MicroVue sC5b-9 Plus EIA, A029; MicroVue Bb Plus EIA, A027, respectively).

\section{Statistical analysis}

For descriptive purposes, continuous variables which were deviated from the normal distribution according to the results of Shapiro-Wilk tests, are given as medians and 25th-75th percentiles. For categorical variables numbers and percentages were used. Non-parametric tests as Mann-Whitney U test or KruskalWallis test with Dunn's post hoc test were used for group comparisons in case of continuous variables. For categorical variables Pearson's $\chi 2$ test was performed. For comparison of the recombinant FHR-5 variants' data, repeated-measures ANOVA was used with Tukey's multiple comparison test.

For cluster analysis hierarchical clustering by Ward method with squared Euclidean distances was used, as described previously (36). 
In order to split FHR-5 levels into high and low groups, receiver operating characteristic analysis was made. Kaplan-Meier analysis with log-rank test was performed to examine patients' renal survival.

For the statistical analysis IBM SPSS Statistics 20 and Graph Pad Prism 5 software were used. Two-tailed p-values were calculated and the significance level was determined at a value of $p<0.05$ if not otherwise stated.

\section{Abbreviations}

aHUS

atypical hemolytic uremic syndrome

AP

alternative pathway

$\mathrm{CP}$

classical pathway

CFHR-1,2,3,4,5

complement Factor H-related protein 1,2,3,4,5

C3G

C3 glomerulopathy

C3GN

C3 glomerulonephritis

$\mathrm{C} 3 \mathrm{NeF}$

C3 nephritic factor

C4NeF

$\mathrm{C} 4$ nephritic factor

C5NeF

C5 nephritic factor

DDD

dense deposit disease

ESRD

end-stage renal disease

FB

Factor B

$\mathrm{FH}$

Factor $\mathrm{H}$

FHR

Factro H-related proteins

IC-MPGN

immune-complex mediated membranoproliferative glomerulonephritis

$\lg \mathrm{AN}$

IgA nephgopathy

MLPA

multiplex ligation-dependent probe ampilification

MPGN

membranoproliferative glomerulonephritis

SPR

surface Plasmon resonance

WT

wild-type

\section{Declarations}

\section{Ethics approval and consent to participate}

Study protocol was approved by the Hungarian Medical Research Council (approval's number: 55381-1/2015/EKU) and the Institutional Review Board of the Semmelweis University, Budapest. Written approvals, based on informed consent, for the diagnostic tests and genetic analysis were given by the patients or their parents in accordance with the Declaration of Helsinki.

Consent for publication:

Not applicable. 
The dataset used and/or analyzed during the current study are available from the corresponding author on reasonable request.

\section{Competing interests:}

The authors declare that they have no competing interests as defined by Nature Research, or other interests that might be perceived to influence the results and/or discussion reported in this paper.

\section{Funding}

This work was supported by the grant of the National Research Fund (National Research, Development and Innovation Office) of Hungary, PD116119 and by the Bolyai János Research Fellowship (2015-2018) to D. Csuka. The research was financed by the Higher Education Institutional Excellence Program of the Ministry of Human Capacities in Hungary, within the framework of the molecular biology thematic program of Semmelweis University. N. Garam received financial support from the EFOP-3.6.3-VEKOP-16-2017-00009 grant. M. Józsi was supported by the Kidneeds Foundation (lowa, USA), the Hungarian Academy of Sciences (nr. 0106307), the Institutional Excellence Program of the Ministry of Human Capacities of Hungary (project nr. 20460-3/2018/FEKUTSTRAT). We also acknowledge support by KMOP-4.2.1./B-10-2011-0002 grant.

\section{Author contribution:}

Study design: Z.P., D.Cs., Á.Sz.,N.G. and M. J.

\section{Acknowledgement}

We thank Beáta Takács, Zsuzsanna Szendrei, Márta Kókai and Erika Kertészné for expert technical assistance. We also thank Blanka Mező and Luca Laszip for their supporting work in this study.

Special thanks to all of the pathologists for their work to evaluate the biopsy: Marijana Ćorić, Merica Glavina Durdov, Prof. Dusan Ferluga, Cosmin Florescu, Danica Galesic, Jaromir Hacek, Prof. Eva Honsova, Béla Iványi, Magdolna Kardos, llona Kaszás, Arvydas Laurinavicius, Prof. Violina Minkova, Dr. Zivile Riispere, Dr. Oleksiy Tsybrovskyy, Nicoleta Petre, Kristýna Pivovarčíková, Thomas Tichy and Prof. Alenka Vizjak.

\section{References}

1. latropoulos P, Noris M, Mele C, Piras R, Valoti E, Bresin E, et al. Complement gene variants determine the risk of immunoglobulin-associated MPGN and C3 glomerulopathy and predict long-term renal outcome. Molecular immunology. 2016;71:131-42. Epub 2016/02/20.

2. Pickering MC, D'Agati VD, Nester CM, Smith RJ, Haas M, Appel GB, et al. C3 glomerulopathy: consensus report. Kidney international. 2013;84(6):1079-89. Epub 2013/11/01.

3. Zhao F, Afonso S, Lindner S, Hartmann A, Loschmann I, Nilsson B, et al. C3-Glomerulopathy Autoantibodies Mediate Distinct Effects on Complement C3and C5-Convertases. Frontiers in immunology. 2019;10:1030. Epub 2019/06/20.

4. Garam N, Prohaszka Z, Szilágyi Á, Aigner C, Schmidt A, Gaggl M, et al. C4 nephritic factor in patients with immune-complex-mediated membranoproliferative glomerulonephritis and C3-glomerulopathy. Orphanet Journal of Rare Diseases. 2019;14(247).

5. Marinozzi MC, Roumenina LT, Chauvet S, Hertig A, Bertrand D, Olagne J, et al. Anti-Factor B and Anti-C3b Autoantibodies in C3 Glomerulopathy and IgAssociated Membranoproliferative GN. Journal of the American Society of Nephrology: JASN. 2017;28(5):1603-13. Epub 2017/01/18.

6. Zhang Y, Meyer NC, Fervenza FC, Lau W, Keenan A, Cara-Fuentes G, et al. C4 Nephritic Factors in C3 Glomerulopathy: A Case Series. American journal of kidney diseases: the official journal of the National Kidney Foundation. 2017;70(6):834-43. Epub 2017/08/26.

7. Sethi S, Fervenza FC, Zhang Y, Zand L, Vrana JA, Nasr SH, et al. C3 glomerulonephritis: clinicopathological findings, complement abnormalities, glomerular proteomic profile, treatment, and follow-up. Kidney international. 2012;82(4):465-73. Epub 2012/06/08.

8. Zhang Y, Meyer NC, Wang K, Nishimura C, Frees K, Jones M, et al. Causes of alternative pathway dysregulation in dense deposit disease. Clinical journal of the American Society of Nephrology: CJASN. 2012;7(2):265-74. Epub 2012/01/10.

9. Licht C, Heinen S, Jozsi M, Loschmann I, Saunders RE, Perkins SJ, et al. Deletion of Lys224 in regulatory domain 4 of Factor $\mathrm{H}$ reveals a novel pathomechanism for dense deposit disease (MPGN II). Kidney international. 2006;70(1):42-50. Epub 2006/04/14.

10. Abrera-Abeleda MA, Nishimura C, Frees K, Jones M, Maga T, Katz LM, et al. Allelic variants of complement genes associated with dense deposit disease. Journal of the American Society of Nephrology: JASN. 2011;22(8):1551-9. Epub 2011/07/26.

11. Wong EK, Anderson HE, Herbert AP, Challis RC, Brown P, Reis GS, et al. Characterization of a factor $\mathrm{H}$ mutation that perturbs the alternative pathway of complement in a family with membranoproliferative GN. Journal of the American Society of Nephrology: JASN. 2014;25(11):2425-33. Epub 2014/04/12.

12. Thomas S, Ranganathan D, Francis L, Madhan K, John GT. Current concepts in C3 glomerulopathy. Indian J Nephrol. 2014;24(6):339-48. Epub 2014/12/09.

13. Cook HT. C3 glomerulopathy. F1000Research. 2017;6:248. Epub 2017/03/31.

14. Riedl M, Thorner P, Licht C. C3 Glomerulopathy. Pediatr Nephrol. 2017;32(1):43-57. Epub 2016/04/09.

Page $17 / 26$ 
15. Hou J, Markowitz GS, Bomback AS, Appel GB, Herlitz LC, Barry Stokes M, et al. Toward a working definition of C3 glomerulopathy by immunofluorescence. Kidney international. 2014;85(2):450-6. Epub 2013/09/27.

16. Figueres ML, Fremeaux-Bacchi V, Rabant M, Galmiche L, Marinozzi MC, Grunfeld JP, et al. Heterogeneous histologic and clinical evolution in 3 cases of dense deposit disease with long-term follow-up. Human pathology. 2014;45(11):2326-33. Epub 2014/09/28.

17. Servais A, Noel LH, Roumenina LT, Le Quintrec M, Ngo S, Dragon-Durey MA, et al. Acquired and genetic complement abnormalities play a critical role in dense deposit disease and other C3 glomerulopathies. Kidney international. 2012;82(4):454-64. Epub 2012/03/30.

18. Iatropoulos P, Daina E, Curreri M, Piras R, Valoti E, Mele C, et al. Cluster Analysis Identifies Distinct Pathogenetic Patterns in C3 Glomerulopathies/Immune Complex-Mediated Membranoproliferative GN. Journal of the American Society of Nephrology: JASN. 2018;29(1):283-94. Epub 2017/10/17.

19. McRae JL, Cowan PJ, Power DA, Mitchelhill KI, Kemp BE, Morgan BP, et al. Human factor H-related protein 5 (FHR-5). A new complement-associated protein. J Biol Chem. 2001;276(9):6747-54. Epub 2000/11/04.

20. Skerka C, Chen Q, Fremeaux-Bacchi V, Roumenina LT. Complement factor H related proteins (CFHRs). Molecular immunology. 2013;56(3):170-80. Epub 2013/07/09.

21. McRae JL, Duthy TG, Griggs KM, Ormsby RJ, Cowan PJ, Cromer BA, et al. Human factor H-related protein 5 has cofactor activity, inhibits C3 convertase activity, binds heparin and C-reactive protein, and associates with lipoprotein. J Immunol. 2005;174(10):6250-6. Epub 2005/05/10.

22. Goicoechea de Jorge E, Caesar JJ, Malik TH, Patel M, Colledge M, Johnson S, et al. Dimerization of complement factor H-related proteins modulates complement activation in vivo. Proc Natl Acad Sci USA. 2013;110(12):4685-90. Epub 2013/03/15.

23. Csincsi Al, Kopp A, Zoldi M, Banlaki Z, Uzonyi B, Hebecker M, et al. Factor H-related protein 5 interacts with pentraxin 3 and the extracellular matrix and modulates complement activation. J Immunol. 2015;194(10):4963-73. Epub 2015/04/10.

24. Zwarthoff SA, Berends ETM, Mol S, Ruyken M, Aerts PC, Jozsi M, et al. Functional Characterization of Alternative and Classical Pathway C3/C5 Convertase Activity and Inhibition Using Purified Models. Frontiers in immunology. 2018;9:1691. Epub 2018/08/08.

25. Zipfel PF, Wiech T, Stea ED, Skerka C. CFHR Gene Variations Provide Insights in the Pathogenesis of the Kidney Diseases Atypical Hemolytic Uremic Syndrome and C3 Glomerulopathy. Journal of the American Society of Nephrology: JASN. 2020;31(2):241-56. Epub 2020/01/26.

26. Abrera-Abeleda MA, Nishimura C, Smith JL, Sethi S, McRae JL, Murphy BF, et al. Variations in the complement regulatory genes factor H (CFH) and factor $\mathrm{H}$ related 5 (CFHR5) are associated with membranoproliferative glomerulonephritis type II (dense deposit disease). J Med Genet. 2006;43(7):582-9. Epub $2005 / 11 / 22$

27. Gale DP, de Jorge EG, Cook HT, Martinez-Barricarte R, Hadjisavvas A, McLean AG, et al. Identification of a mutation in complement factor H-related protein 5 in patients of Cypriot origin with glomerulonephritis. Lancet. 2010;376(9743):794-801. Epub 2010/08/31.

28. Gale DP, Maxwell PH. C3 glomerulonephritis and CFHR5 nephropathy. Nephrology, dialysis, transplantation: official publication of the European Dialysis and Transplant Association -. European Renal Association. 2013;28(2):282-8. Epub 2012/11/06.

29. Westra D, Vernon KA, Volokhina EB, Pickering MC, van de Kar NC, van den Heuvel LP. Atypical hemolytic uremic syndrome and genetic aberrations in the complement factor H-related 5 gene. Journal of human genetics. 2012;57(7):459-64. Epub 2012/05/25.

30. Monteferrante G, Brioschi S, Caprioli J, Pianetti G, Bettinaglio P, Bresin E, et al. Genetic analysis of the complement factor H related 5 gene in haemolytic uraemic syndrome. Molecular immunology. 2007;44(7):1704-8. Epub 2006/09/27.

31. Zhai YL, Meng SJ, Zhu L, Shi SF, Wang SX, Liu LJ, et al. Rare Variants in the Complement Factor H-Related Protein 5 Gene Contribute to Genetic Susceptibility to IgA Nephropathy. Journal of the American Society of Nephrology: JASN. 2016;27(9):2894-905. Epub 2016/01/31.

32. Zhu L, Guo WY, Shi SF, Liu LJ, Lv JC, Medjeral-Thomas NR, et al. Circulating complement factor H-related protein 5 levels contribute to development and progression of IgA nephropathy. Kidney international. 2018;94(1):150-8. Epub 2018/05/16.

33. Medjeral-Thomas NR, Lomax-Browne HJ, Beckwith H, Willicombe M, McLean AG, Brookes P, et al. Circulating complement factor H-related proteins 1 and 5 correlate with disease activity in IgA nephropathy. Kidney international. 2017;92(4):942-52. Epub 2017/07/05.

34. Vernon KA, Goicoechea de Jorge E, Hall AE, Fremeaux-Bacchi V, Aitman TJ, Cook HT, et al. Acute presentation and persistent glomerulonephritis following streptococcal infection in a patient with heterozygous complement factor H-related protein 5 deficiency. American journal of kidney diseases: the official journal of the National Kidney Foundation. 2012;60(1):121-5. Epub 2012/04/17.

35. Osborne AJ, Breno M, Borsa NG, Bu F, Fremeaux-Bacchi V, Gale DP, et al. Statistical Validation of Rare Complement Variants Provides Insights into the Molecular Basis of Atypical Hemolytic Uremic Syndrome and C3 Glomerulopathy. J Immunol. 2018;200(7):2464-78. Epub 2018/03/04.

36. Garam N, Prohaszka Z, Szilágyi Á, Aigner C, Schmidt A, Gaggl M, et al. Validation of distinct pathogenic patterns in a cohort of membranoproliferative glomerulonephritis patients by cluster analysis. Clinical kidney journal. 2019:1-10.

37. Murphy B, Georgiou T, Machet D, Hill P, McRae J. Factor H-related protein-5: a novel component of human glomerular immune deposits. American journal of kidney diseases: the official journal of the National Kidney Foundation. 2002;39(1):24-7. Epub 2002/01/05.

38. van Beek AE, Pouw RB, Brouwer MC, van Mierlo G, Geissler J, Ooijevaar-de Heer P, et al. Factor H-Related (FHR)-1 and FHR-2 Form Homo- and Heterodimers, while FHR-5 Circulates Only As Homodimer in Human Plasma. Frontiers in immunology. 2017;8:1328. Epub 2017/11/03.

39. Chen Q, Manzke M, Hartmann A, Buttner M, Amann K, Pauly D, et al. Complement Factor H-Related 5-Hybrid Proteins Anchor Properdin and Activate Complement at Self-Surfaces. Journal of the American Society of Nephrology: JASN. 2016;27(5):1413-25. Epub 2015/10/04.

40. Rudnick RB, Chen Q, Stea ED, Hartmann A, Papac-Milicevic N, Person F, et al. FHR5 Binds to Laminins, Uses Separate C3b and Surface-Binding Sites, and Activates Complement on Malondialdehyde-Acetaldehyde Surfaces. J Immunol. 2018;200(7):2280-90. Epub 2018/02/28.

41. Prasto J, Kaplan BS, Russo P, Chan E, Smith RJ, Meyers KE. Streptococcal infection as possible trigger for dense deposit disease (C3 glomerulopathy). Eur J Pediatrics. 2014;173(6):767-72. Epub 2014/01/05. 
42. Ferreira VP, Pangburn MK, Cortes C. Complement control protein factor $\mathrm{H}$ : the good, the bad, and the inadequate. Molecular immunology. 2010;47(13):2187-97. Epub 2010/06/29.

43. Levine AP, Chan MMY, Sadeghi-Alavijeh O, Wong EKS, Cook HT, Ashford S, et al. Large-Scale Whole-Genome Sequencing Reveals the Genetic Architecture of Primary Membranoproliferative GN and C3 Glomerulopathy. Journal of the American Society of Nephrology: JASN. 2020;31(2):365-73. Epub 2020/01/11.

44. Szarvas N, Szilagyi A, Csuka D, Takacs B, Rusai K, Muller T, et al. Genetic analysis and functional characterization of novel mutations in a series of patients with atypical hemolytic uremic syndrome. Molecular immunology. 2016;71:10-22. Epub 2016/01/31.

45. Adzhubei IA, Schmidt S, Peshkin L, Ramensky VE, Gerasimova A, Bork P, et al. A method and server for predicting damaging missense mutations. Nature methods. 2010;7(4):248-9. Epub 2010/04/01.

46. Ng PC, Henikoff S. Predicting deleterious amino acid substitutions. Genome research. 2001;11(5):863-74. Epub 2001/05/05.

47. Choi Y, Sims GE, Murphy S, Miller JR, Chan AP. Predicting the functional effect of amino acid substitutions and indels. PloS one. 2012;7(10):e46688. Epub 2012/10/12.

48. Desmet FO, Hamroun D, Lalande M, Collod-Beroud G, Claustres M, Beroud C. Human Splicing Finder: an online bioinformatics tool to predict splicing signals. Nucleic acids research. 2009;37(9):e67. Epub 2009/04/03.

49. Schwarz JM, Rodelsperger C, Schuelke M, Seelow D. MutationTaster evaluates disease-causing potential of sequence alterations. Nature methods. 2010;7(8):575-6. Epub 2010/08/03.

50. Kuhn S, Zipfel PF. The baculovirus expression vector pBSV-8His directs secretion of histidine-tagged proteins. Gene. 1995;162(2):225-9. Epub 1995/09/11.

51. Fetterhoff TJ, McCarthy RC. A micromodification of the CH50 test for the classical pathway of complement. J Clin Lab Immunol. 1984;14(4):205-8. Epub 1984/08/01.

52. Reti M, Farkas P, Csuka D, Razso K, Schlammadinger A, Udvardy ML, et al. Complement activation in thrombotic thrombocytopenic purpura. Journal of thrombosis haemostasis: JTH. 2012;10(5):791-8. Epub 2012/03/01.

53. Delamarche C, Berger F, Pouplard A, Emile J. An ELISA technique for the measurement of C1q in cerebrospinal fluid. J Immunol Methods. 1988;114(12):101-6. Epub 1988/11/10.

54. Dragon-Durey MA, Loirat C, Cloarec S, Macher MA, Blouin J, Nivet $\mathrm{H}$, et al. Anti-Factor $\mathrm{H}$ autoantibodies associated with atypical hemolytic uremic syndrome. Journal of the American Society of Nephrology: JASN. 2005;16(2):555-63. Epub 2004/12/14.

55. Rother U. A new screening test for C3 nephritis factor based on a stable cell bound convertase on sheep erythrocytes. J Immunol Methods. 1982;51(1):101-7. Epub 1982/01/01

56. Tao J, Lieberman J, Lafayette RA, Kambham N. A rare case of Alport syndrome, atypical hemolytic uremic syndrome and Pauci-immune crescentic glomerulonephritis. BMC Nephrol. 2018;19(1):355. Epub 2018/12/14.

57. Provaznikova D, Rittich S, Malina M, Seeman T, Marinov I, Riedl M, et al. Manifestation of atypical hemolytic uremic syndrome caused by novel mutations in MCP. Pediatr Nephrol. 2012;27(1):73-81. Epub 2011/06/28.

58. Bresin E, Rurali E, Caprioli J, Sanchez-Corral P, Fremeaux-Bacchi V, Rodriguez de Cordoba S, et al. Combined complement gene mutations in atypical hemolytic uremic syndrome influence clinical phenotype. Journal of the American Society of Nephrology: JASN. 2013;24(3):475-86. Epub 2013/02/23.

59. Mohlin FC, Mercier E, Fremeaux-Bacchi V, Liszewski MK, Atkinson JP, Gris JC, et al. Analysis of genes coding for CD46, CD55, and C4b-binding protein in patients with idiopathic, recurrent, spontaneous pregnancy loss. Eur J Immunol. 2013;43(6):1617-29. Epub 2013/03/20.

60. Fidalgo T, Martinho P, Pinto CS, Oliveira AC, Salvado R, Borras N, et al. Combined study of ADAMTS13 and complement genes in the diagnosis of thrombotic microangiopathies using next-generation sequencing. Research practice in thrombosis haemostasis. 2017;1(1):69-80. Epub 2018/07/27.

61. Seddon JM, Yu Y, Miller EC, Reynolds R, Tan PL, Gowrisankar S, et al. Rare variants in CFI, C3 and C9 are associated with high risk of advanced agerelated macular degeneration. Nat Genet. 2013;45(11):1366-70. Epub 2013/09/17.

62. Yuasa I, Nakagawa M, Umetsu K, Harihara S, Matsusue A, Nishimukai H, et al. Molecular basis of complement factor I (CFI) polymorphism: one of two polymorphic suballeles responsible for CFI A is Japanese-specific. Journal of human genetics. 2008;53(11-12):1016-21. Epub 2008/10/01.

63. Kavanagh D, Richards A, Noris M, Hauhart R, Liszewski MK, Karpman D, et al. Characterization of mutations in complement factor I (CFI) associated with hemolytic uremic syndrome. Molecular immunology. 2008;45(1):95-105. Epub 2007/06/29.

64. Roversi P, Johnson S, Caesar JJ, McLean F, Leath KJ, Tsiftsoglou SA, et al. Structural basis for complement factor I control and its disease-associated sequence polymorphisms. Proc Natl Acad Sci USA. 2011;108(31):12839-44. Epub 2011/07/20.

65. Caprioli J, Noris M, Brioschi S, Pianetti G, Castelletti F, Bettinaglio P, et al. Genetics of HUS: the impact of MCP, CFH, and IF mutations on clinical presentation, response to treatment, and outcome. Blood. 2006;108(4):1267-79. Epub 2006/04/20.

66. Sartz L, Olin Al, Kristoffersson AC, Stahl AL, Johansson ME, Westman K, et al. A novel C3 mutation causing increased formation of the C3 convertase in familial atypical hemolytic uremic syndrome. J Immunol. 2012;188(4):2030-7. Epub 2012/01/18.

67. Fang CJ, Fremeaux-Bacchi V, Liszewski MK, Pianetti G, Noris M, Goodship TH, et al. Membrane cofactor protein mutations in atypical hemolytic uremic syndrome (aHUS), fatal Stx-HUS, C3 glomerulonephritis, and the HELLP syndrome. Blood. 2008;111(2):624-32. Epub 2007/10/05.

68. Richards A, Kathryn Liszewski M, Kavanagh D, Fang CJ, Moulton E, Fremeaux-Bacchi V, et al. Implications of the initial mutations in membrane cofactor protein (MCP; CD46) leading to atypical hemolytic uremic syndrome. Molecular immunology. 2007;44(1-3):111-22. Epub 2006/08/03.

69. Bu F, Maga T, Meyer NC, Wang K, Thomas CP, Nester CM, et al. Comprehensive genetic analysis of complement and coagulation genes in atypical hemolytic uremic syndrome. Journal of the American Society of Nephrology: JASN. 2014;25(1):55-64. Epub 2013/09/14.

Page $19 / 26$ 
70. Kernan KF, Ghaloul-Gonzalez L, Shakoory B, Kellum JA, Angus DC, Carcillo JA. Adults with septic shock and extreme hyperferritinemia exhibit pathogenic immune variation. Genes Immun. 2019;20(6):520-6. Epub 2018/07/07.

71. Narendra U, Pauer GJ, Hagstrom SA. Genetic analysis of complement factor H related 5, CFHR5, in patients with age-related macular degeneration. Molecular vision. 2009;15:731-6. Epub 2009/04/15.

\section{Figures}

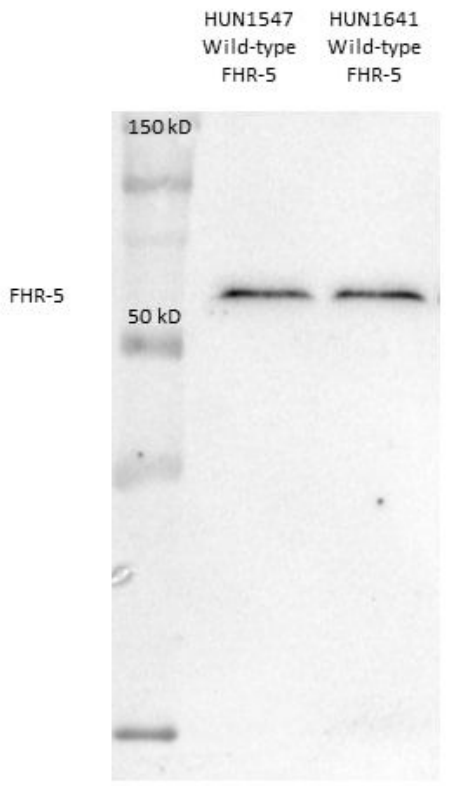

Figure 1

FHR-5 on Western Blot. Two serum samples obtained from patients with wild-type FHR-5 protein were analyzed. 


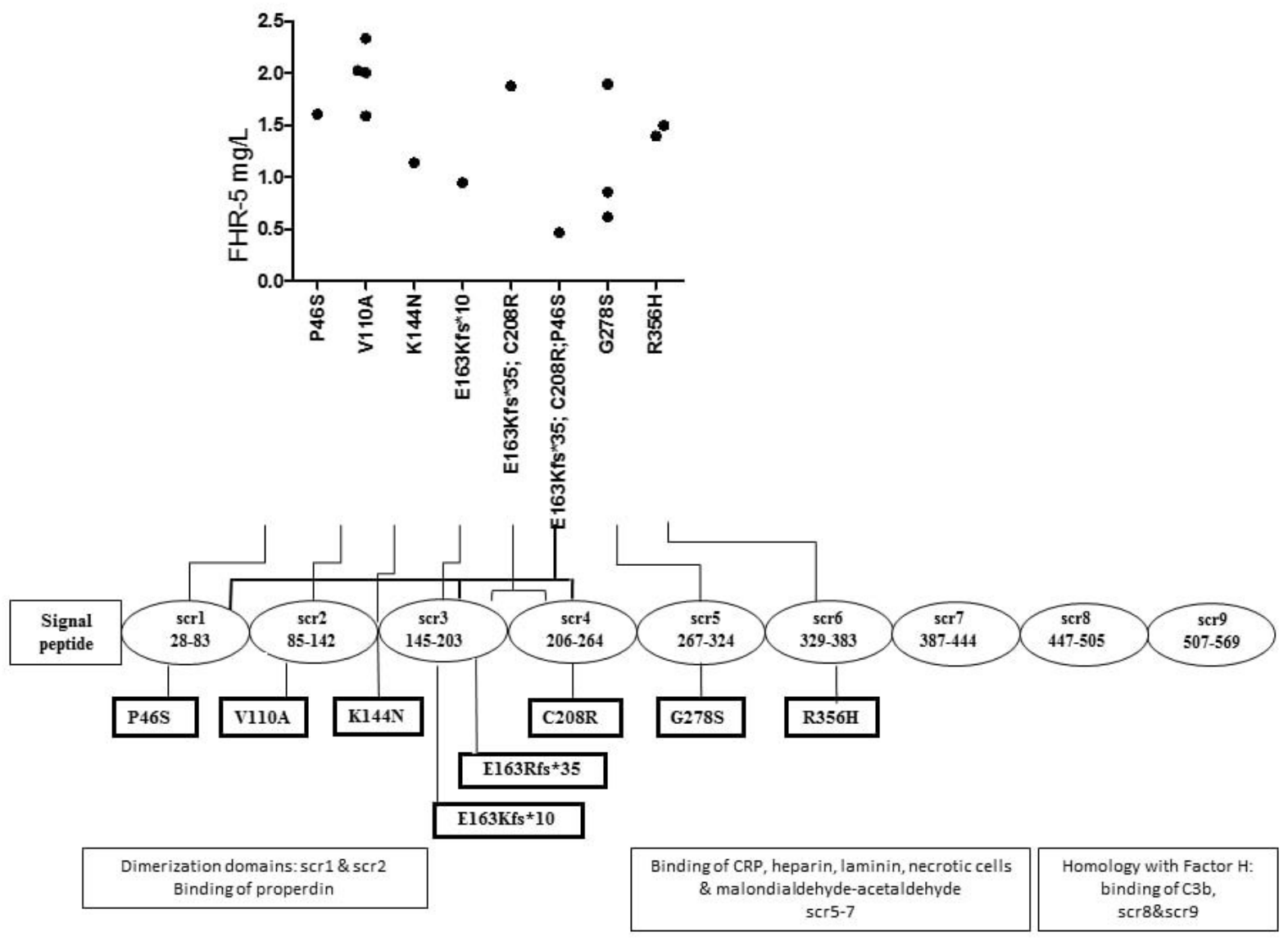

Figure 2

Localization of missense and frame-shift CFHR5 variations and the serum level of FHR-5. 


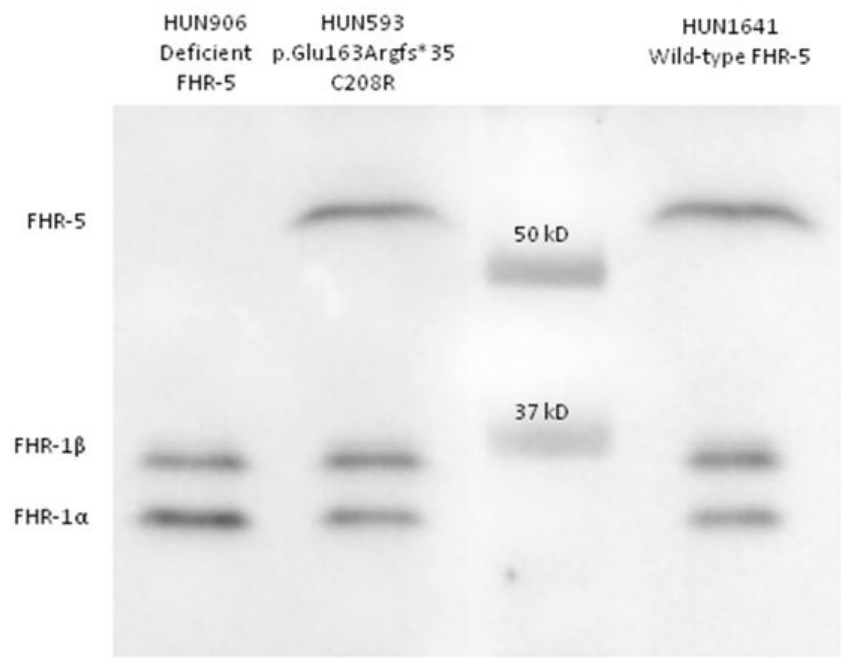

Figure 3

Western blot of the patient (HUN593) carrying two mutations in CFHR5, by using polyclonal anti-FHR-5 antibody. Samples of patient HUN906 (having complete deficiency of FHR-5) and HUN1641 (wild-type FHR-5) are shown for reference.

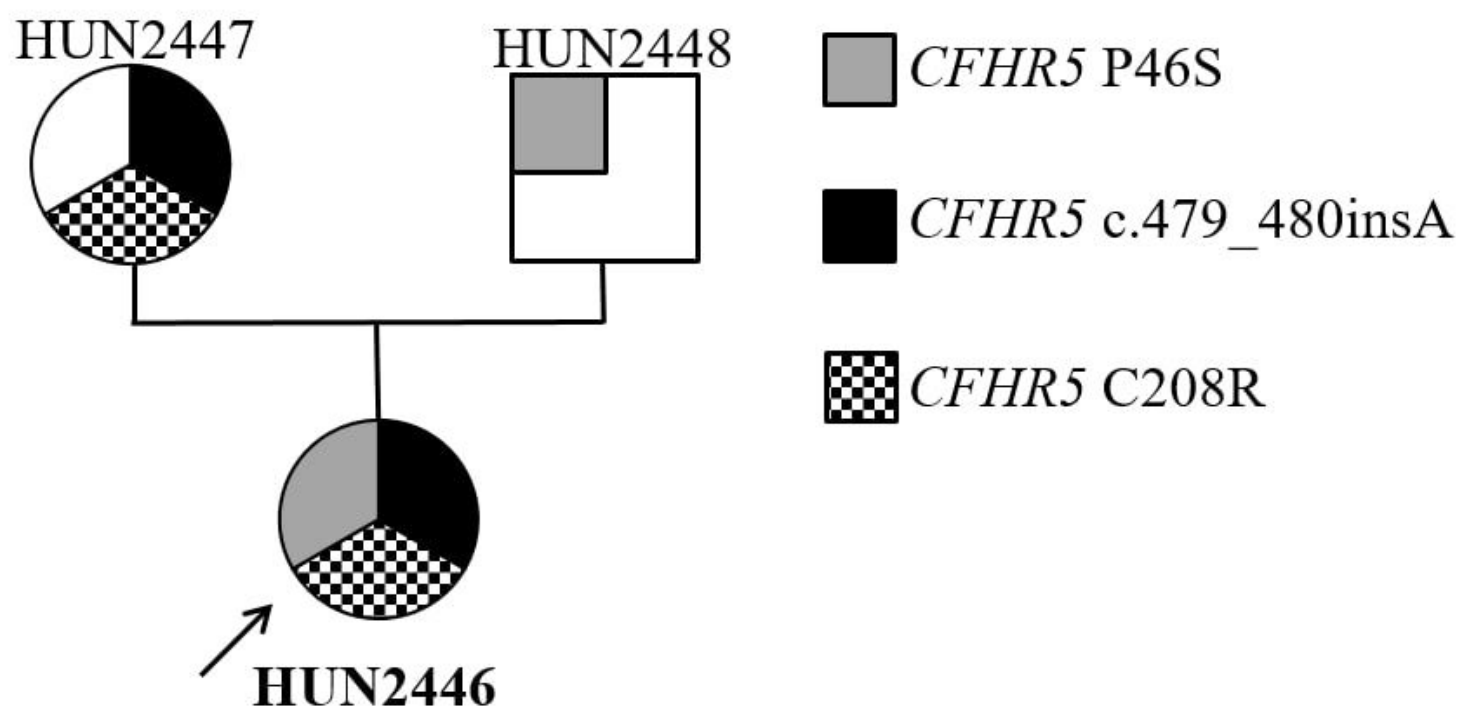

Figure 4

Family tree representing the inheritance of the CFHR5 P46S, c.479_480insA and C208R mutations in the family of HUN2446. 


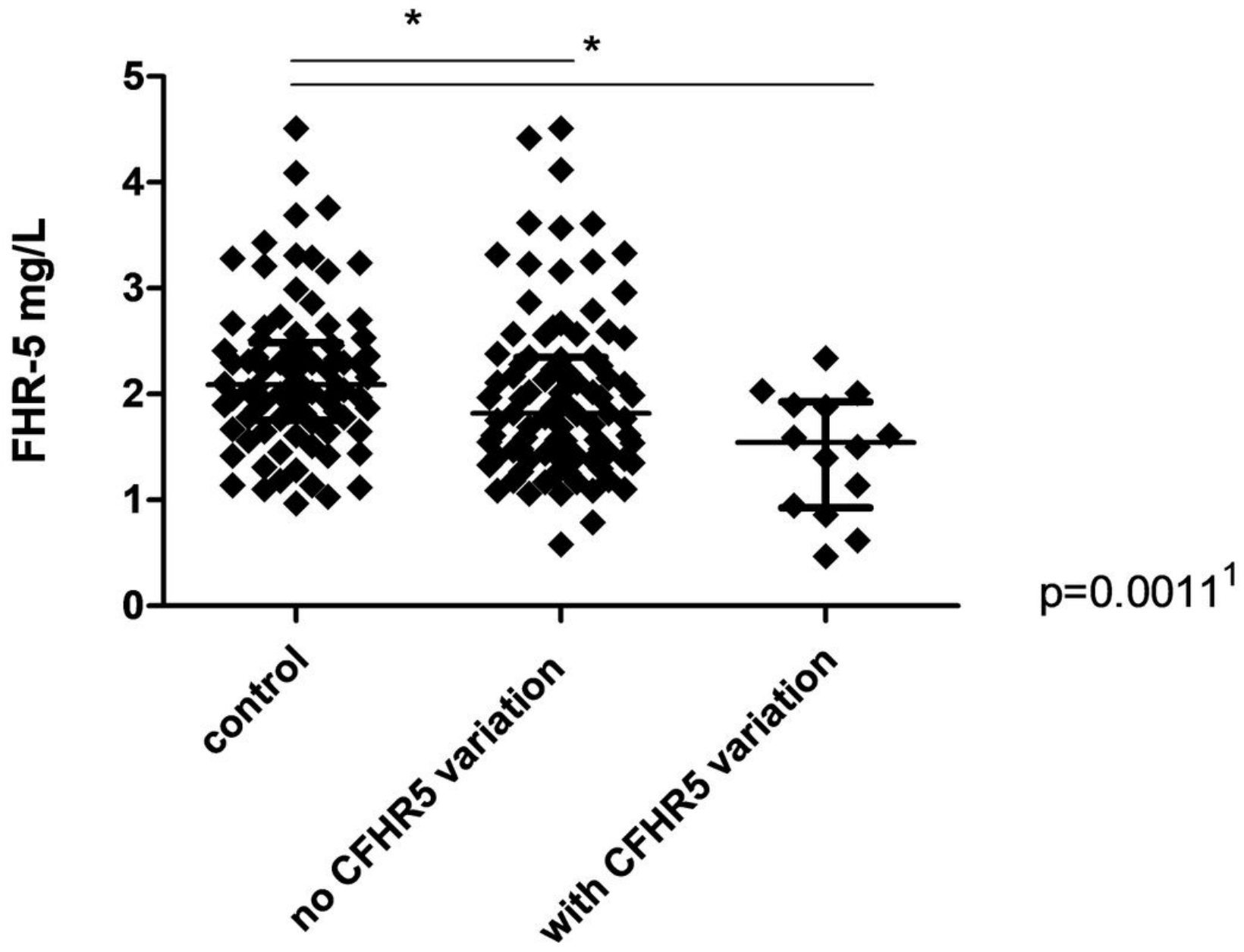

Figure 5

FHR-5 levels in patients with C3G/IC-MPGN and in healthy individuals $1 p$-value was determined with ANOVA. * $p<0.05$ by Dunn post test. 
A

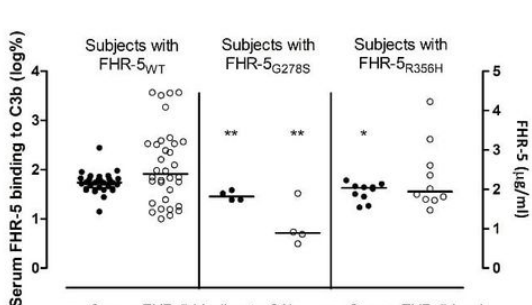

B

- Serum FHR-5 binding to C3b o Serum FHR-5 level

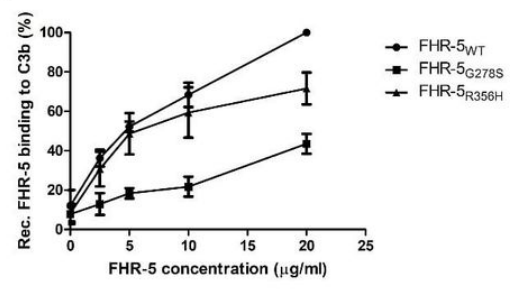

C
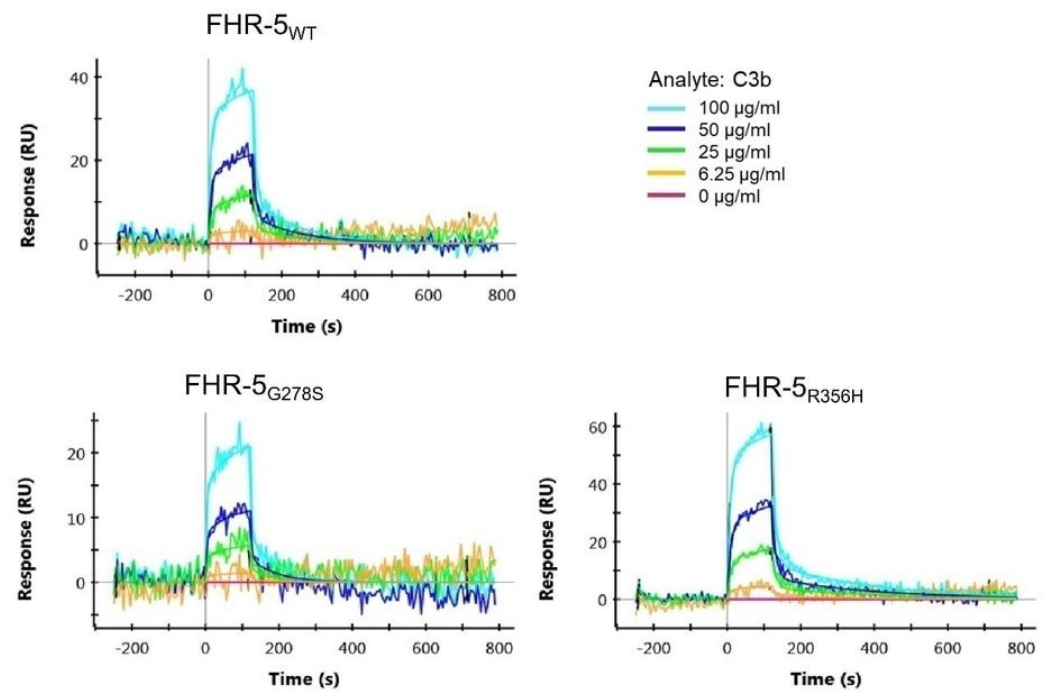

\begin{tabular}{c|c|c|c} 
& $\mathbf{k}_{\mathbf{a}}(\mathbf{1} / \mathbf{M s})$ & $\mathbf{k}_{\mathbf{d}}(\mathbf{1} / \mathbf{s})$ & $\mathbf{K}_{\mathbf{D}}(\mathbf{M})$ \\
\hline FHR-5 $_{W T}$ & $2.67 \times 10^{4}$ & $1.41 \times 10^{-1}$ & $5.26 \times 10^{-6}$ \\
FHR-5 $_{\text {G278S }}$ & $1.27 \times 10^{4}$ & $2.6 \times 10^{-1}$ & $2.05 \times 10^{-5}$ \\
FHR-5 $_{\text {R } 356 \mathrm{H}}$ & $1.80 \times 10^{4}$ & $1.01 \times 10^{-1}$ & $5.60 \times 10^{-6}$
\end{tabular}

\section{Figure 6}

A) Comparison of serum FHR-5 levels and serum FHR-5 C3b binding ability of patients with only FHR-5WT and those carrying also FHR-5G278S or FHR5R356H in ELISA. C3b was immobilized, then serum was added and FHR-5 was detected by polyclonal anti-FHR-5. Dots represent individual patients. Data are mean of two measurements and are normalized to a calibrator sample containing only FHR-5WT. Subjects expressing FHR-5G278S show significantly lower FHR-5 levels and C3b binding compared to the FHR-5WT expressing group. Serum FHR-5 levels were measured in a sandwich ELISA. Circles represent individual patients. Data are mean of two measurements. FHR-5 levels of patients with FHR-5R356H does not differ from the FHR-5WT expressing group, but it shows decreased C3b binding ability (Kruskal-Wallis test with Dunn's post test, **: $p<0.01, *: p<0.05$ ). B) Dose-dependent binding of recombinant FHR-5WT, FHR-5G278S and FHR-5R356H to purified C3b measured in ELISA. The FHR-5G278S variant binds significantly weaker to C3b (one-way ANOVA with Bonferroni's post test, $p<0.01$ ). Data are mean of four measurements \pm SEM. C) Interaction of C3b-FHR-5 variants measured by SPR. C3b in serial dilutions were flown over immobilized FHR-5 variants. The KD of the C3b-FHR-5G278S is one order greater compared to that of C3b-FHR-5R356H and C3b-FHR-5WT. Data are representative of two experiments. 


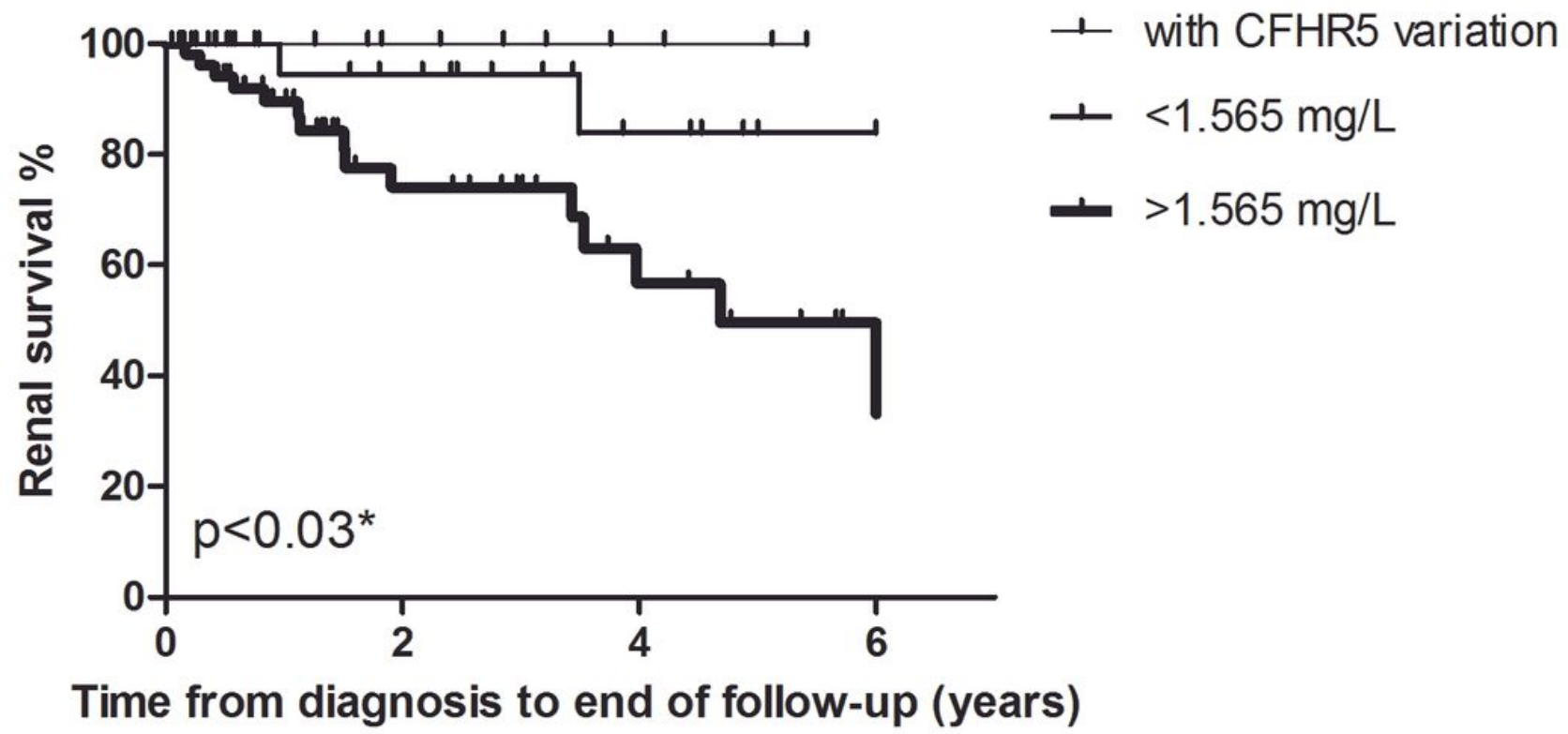

\begin{tabular}{|l|c|c|c|c|}
\hline $\begin{array}{l}\text { Subjects at } \\
\text { risk }\end{array}$ & 0 & 2 & 4 & 6 \\
\hline $\begin{array}{l}\text { with CFHR5 } \\
\text { variation }\end{array}$ & 13 & 7 & 3 & 0 \\
\hline$<1.565 \mathrm{mg} / \mathrm{L}$ & 28 & 15 & 7 & 1 \\
\hline$>1.565 \mathrm{mg} / \mathrm{L}$ & 52 & 20 & 9 & 2 \\
\hline
\end{tabular}

Figure 7

Patients' renal survival according to their FHR-5 serum levels * $\mathrm{p}$-value was determined by log-rank test comparing patients with high and low FHR- 5 serum levels

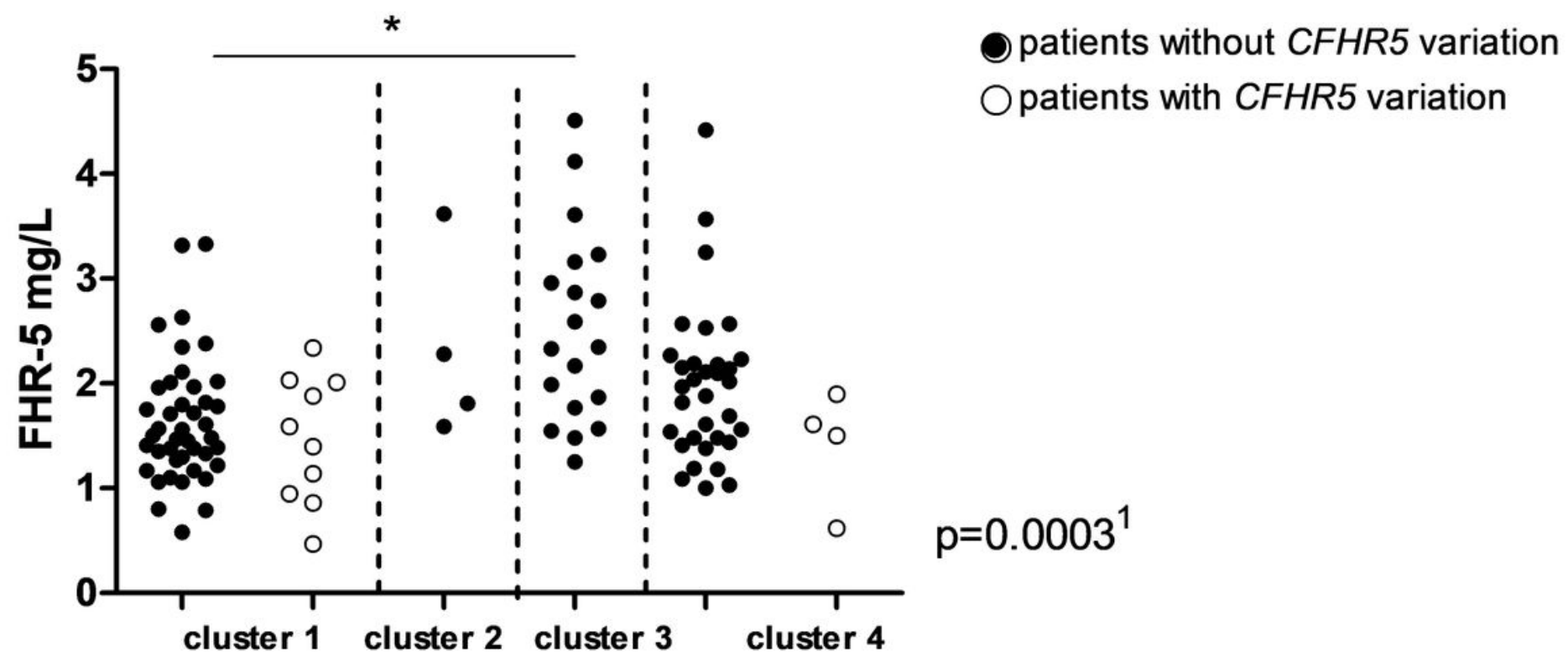

Figure 8 
FHR-5 protein levels in the previously described clusters of C3G/IC-MPGN patients $(18,35)$. The clinically meaningful clusters were generated based on clinical, histological, genetic and complement data of patients as described by latropoulos et al. Each dot represents one patient. 1p-value was determined with ANOVA for patients without CFHR5 variations comparing patients in cluster 1,3 and $4 .{ }^{*} p<0.05$ by Dunn post test, for patients without CFHR5 variations. 